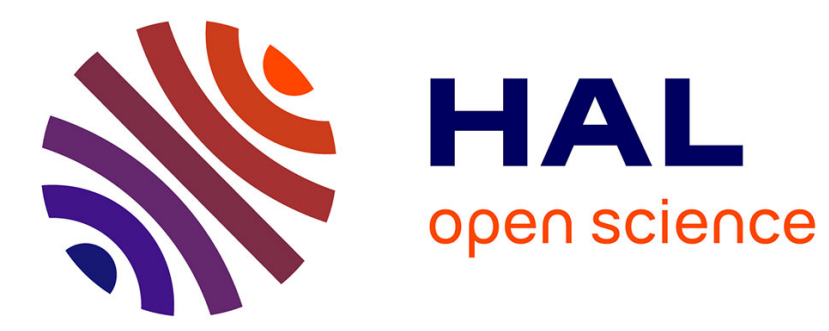

\title{
Long-term growth of the Himalaya inferred from interseismic InSAR measurement
}

Raphael Grandin, Marie-Pierre Doin, Laurent Bollinger, Béatrice

Pinel-Puysségur, Gabriel Ducret, Romain Jolivet, S. N. Nath Sapkota

\section{To cite this version:}

Raphael Grandin, Marie-Pierre Doin, Laurent Bollinger, Béatrice Pinel-Puysségur, Gabriel Ducret, et al.. Long-term growth of the Himalaya inferred from interseismic InSAR measurement. Geology, 2012, 40 (12), pp.1059 - 1062. 10.1130/G33154.1 . hal-01621509

\section{HAL Id: hal-01621509 \\ https://hal.science/hal-01621509}

Submitted on 23 Oct 2017

HAL is a multi-disciplinary open access archive for the deposit and dissemination of scientific research documents, whether they are published or not. The documents may come from teaching and research institutions in France or abroad, or from public or private research centers.
L'archive ouverte pluridisciplinaire HAL, est destinée au dépôt et à la diffusion de documents scientifiques de niveau recherche, publiés ou non, émanant des établissements d'enseignement et de recherche français ou étrangers, des laboratoires publics ou privés. 
9 Kathmandu, Nepal

\section{ABSTRACT}

Publisher: GSA

Journal: GEOL: Geology

Article ID: G33154

\section{Long-term growth of the Himalaya inferred from} interseismic InSAR measurement ${ }^{1}$

\section{Puysségur $^{2}$, Gabriel Ducret ${ }^{1}$, Romain Jolivet ${ }^{3}$, and Soma Nath Sapkota ${ }^{4}$}

${ }^{1}$ Ecole Normale Supérieure, UMR 8538, F-75231 Paris, France

${ }^{2} C E A, D A M, D I F$, F-91297 Arpajon, France

${ }^{3}$ Institut des Sciences de la Terre, UMR 5275, F-38041 Grenoble, France

${ }^{4}$ Department of Mines and Geology, National Seismological Centre, Lainchaur,

The rise and support of the $\sim 5000$ m topographic scarp at the front of IndianEurasian collision in the Himalaya involves long-term uplift above a mid-crustal ramp within the Main Himalayan Thrust (MHT) system. Locking of the shallower portion of the flat-ramp-flat during the interseismic period also produces transient uplift above the transition zone. However, spatial and temporal relationships between permanent and transient vertical deformation in the Himalaya are poorly constrained, leading to an unresolved causal relationship between the two. Here, we use synthetic aperture radar interferometry (InSAR) to measure interseismic uplift on a transect crossing the whole Himalaya in Central Nepal. The uplift velocity of $7 \mathrm{~mm} / \mathrm{yr}$ at the front of the Annapurnas is explained by a $18-21 \mathrm{~mm} / \mathrm{yr}$ slip rate on the deep shallow-dipping portion of the MHT, with full locking of the mid-crustal ramp underlying the High Range. The transient uplift peak observed by InSAR matches spatially with the long-term uplift peak deduced from

1 Article accepted for publication in Geology on 18 May 2012.

Page 1 of 16 
involving thrusting over a ramp of fixed geometry predict a $\sim 20 \mathrm{~km}$ separation between

the two peaks. We argue that this coincidence indicates that today's mid-crustal ramp in

27 Central Nepal is located southward with respect to its average long-term location,

suggesting that mountain growth proceeds by frontward migration of the ramp driven by underplating of material from the Indian plate under the Himalaya.

\section{0}


Publisher: GSA

Journal: GEOL: Geology

Article ID: G33154

intense rainfall along the orographic barrier (e.g., Hodges et al., 2004 ; Wobus et al., 2005).

During the interseismic period, the shallowest portion of MHT is locked.

Constraining the location of the locking boundary within the MHT should permit us to pinpoint which up-dip portion of the MHT contributes most to long-term uplift in the Himalaya: a steep fault emerging near the MCT or the ramp-flat connection to MFT. Resolving this question could help to identify the most probable scenario among these two radically different views on the evolution of the Himalayan orogeny.

INSAR MEASUREMENT OF SURFACE VELOCITY FIELD

Using satellite-borne synthetic aperture radar interferometry (InSAR), we map the interseismic velocity field across the Himalayan range. In this region, the poor coherence is the primary obstacle to InSAR measurements. To tackle this issue, we apply a series of corrections that improve the spatial coherence of wrapped interferograms (see the GSA Data Repository ${ }^{1}$ ). We use 29 C-band SAR images acquired between 2003 and 2010 over Western-Central Nepal. The images are precisely coregistered with respect to a single master image, and interferograms are computed using an a priori knowledge of topography to curb the impact of image distortion and limit geometrical decorrelation (Doin et al., 2011). A small-baseline strategy is implemented to take advantage of the redundancy on phase information and compensate for phase noise (Pinel-Puysségur et al., 2011). Digital elevation model (DEM) errors are determined by exploiting the proportionality between the perpendicular baseline and the local (wrapped) phase variability within the interferometric network (Ducret et al., 2011). Using independent atmospheric data provided by the ERA-Interim reanalysis of European Centre for 
Publisher: GSA

Journal: GEOL: Geology

Article ID: G33154

geodetic data set combined here for the measurement of interseismic strain in Nepal (InSAR, leveling and GPS) is internally consistent.

The simplest hypothesis on the cause of interseismic strain in Nepal is continuous

aseismic creep on the deep portion of the MHT, while its shallow portion from the latitude of the high Range to the MFT is locked (Fig. 2) (Vergne et al., 2001). Here, we model the creeping fault as a planar semi-infinite dislocation embedded in an elastic half space (Okada, 1985), and we invert separately the geodetic data of East- and WestCentral Nepal to infer possible lateral variations in the configuration of the MHT. Fault strike and rake are fixed to simulate a convergence direction of $\mathrm{N} 10^{\circ} \mathrm{E}$ in West-Central Nepal and $\mathrm{N} 05^{\circ} \mathrm{E}$ in East-Central Nepal, which accounts for the curvature of the plate boundary. Using a combination of horizontal (GPS) and vertical (InSAR or leveling) data, we invert for the depth of the top of the dislocation, its dip angle, and its slip rate using a nonlinear inversion method (Tarantola and Valette, 1982). The comparison of the inversion results shows that fault geometry and slip rate cannot be distinguished between East- and West-Central Nepal within the uncertainty of the data, suggesting that lateral variations of the properties of the MHT in Central Nepal are small (Fig. 2). The preferred model indicates that interseismic deformation is induced by a fault dipping at $3-7^{\circ}$, buried at a depth of $20-24 \mathrm{~km}$, with a slip rate of $18-21 \mathrm{~mm} / \mathrm{yr}$. This inferred deep creeping portion of the MHT appears to correspond with a seismically imaged lowvelocity zone under southern Tibet (Nábělek et al., 2009). The up-dip projection of the modeled dislocation intersects the surface well to the south of the active trace of the MFT (see Fig. 2), suggesting that the MHT dips on average more steeply at seismogenic depth than at greater depth in the stable-sliding domain. This is consistent with the flat-ramp- 
115

116

Publisher: GSA

Journal: GEOL: Geology

Article ID: G33154

flat geometry of the underlying MHT that has been inferred from the long-recognized antiformal structure of the Lesser Himalaya (Fig. 2) (Schelling, 1992).

\section{DISCUSSION}

Current deformation measured by geodesy indicates that deep aseismic creep terminates at the bottom of the mid-crustal ramp, which is consistent with full locking of the ramp and frontal flat during the interseismic period. Great historical earthquakes are believed to be caused by rupture of this locked portion of the fault system, thereby compensating the deformation accumulated during the interseismic period. However, due to the non-planar geometry of the MHT, permanent deformation is expected to remain after each seismic cycle, which should be manifested by a net uplift centered above the mid-crustal ramp. Therefore, if thrusting occurred over a mid-crustal ramp with a fixed geometry, a $\sim 20 \mathrm{~km}$ north-south separation should be observed between the transient (interseismic, above the base of the ramp) and permanent (long-term, above the middle of the ramp) peaks of uplift (Cattin and Avouac, 2000) (Fig. 3a).

On the other hand, the study of trans-Himalayan river profiles provides constraints on the denudation processes that compete with this expected long-term uplift (Lavé and Avouac, 2001; Seeber and Gornitz, 1983; Meade, 2010). This independent geomorphological approach indicates that the locus of maximum long-term uplift is actually situated at the same latitude as the interseismic uplift peak measured by geodesy from InSAR and leveling (Fig. 2).

This spatial correspondence conflicts with the prediction, but can be accounted for by several interpretations. Long-term and interseismic uplift could be colocated if coseismic deformation related to slip on the MFT were not sufficient to compensate for 
Publisher: GSA

Journal: GEOL: Geology

Article ID: G33154

interseismic uplift (Bilham et al., 1997; Meade, 2010). Indeed, although

geomorphological evidence above the MFT indicate that nearly all of the shortening between Tibet and India is accommodated at the front of the system, suggesting no or little convergence deficit on the MFT (Lavé and Avouac, 2001), it is difficult to rule out the possibility of a few $\mathrm{mm} / \mathrm{yr}$ of permanent shortening in the High Himalaya. Thus, a recently proposed mechanism is the out-of-sequence activation of a new thrust fault intersecting the surface $0-35 \mathrm{~km}$ to the south of the mapped trace of MCT, and outcropping near the break in topographic slope identified as a physiographic transition $\left(\mathrm{PT}_{2}\right)$ (Wobus et al., 2005) (Figs. 1 and 3b). However, our inversions show that the base of the locked portion of the MHT is located at a depth of $\sim 20 \mathrm{~km}$, between $0 \mathrm{~km}$ and 20 $\mathrm{km}$ to the South of $\mathrm{PT}_{2}$ (Fig. 1). If a thrust fault connected $\mathrm{PT}_{2}$ with the locking transition of the MHT, then the observed spatial matching between long-term and interseismic uplift would require an extremely high dip angle for this hypothesized fault $\left(45-90^{\circ}\right)$.

Such a steep dip angle would be incompatible with theoretical constraints on reverse fault geometry provided by rock mechanics.

An alternative model of mountain building postulates that a strong topographic gradient within the overriding block may be created by accretion of material from the footwall to the hanging wall across the main thrust boundary (Fig. 3c) (Robinson et al., 2003). Over several million years, numerical simulations of this underplating process assume a continuous flux of material across the mid-crustal ramp (Bollinger et al., 2006). However, on smaller time scales, accretion likely proceeds by discontinuous ramp jumps toward the foreland, leading to the formation of a crustal-scale duplex (Schelling, 1992). Migration of the ramp is expected to produce a gradual southward migration of the 
topographic front that would tend to be competed by erosion. In the case of rapid erosion

161 processes, a steady-state situation should emerge, where the peak of long-term uplift,

162 which should roughly correspond to the location of the ramp, should be at any time

163 located south of the peak of transient interseismic uplift (Burbank et al., 2003). Yet, the

164 locus of maximum long-term denudation rate - which reflects the result of the

165 competition between erosion processes and rock uplift — appears to be located to the

166 north of the latitude of today's mid-crustal ramp inferred from our inversions, indicating

167 that the system is out-of-equilibrium. Alternatively, the observed coincidence between the

168 peak of interseismic uplift (marking the surface projection of the locked-to-unlocked

169 transition on the MHT) and the peak of long-term uplift (marking the average position of

170 the ramp over a period of time greatly exceeding the duration of a seismic cycle) could be

171 compatible with delayed erosional response to a recent southward migration of the ramp.

172 Assuming that a $20 \mathrm{~km}$ north-south offset between the two peaks is achieved when the

173 geometry remains fixed (Cattin and Avouac, 2000), and if erosion operates on time scales

174 of 0.1-1 m.y. (Lavé and Avouac, 2001), then the preservation of a coincidence between

175 the two peaks requires an apparent ramp migration velocity of $20-200 \mathrm{~mm} / \mathrm{yr}$. This rate

176 largely exceeds the average overthrusting rate of $5 \mathrm{~mm} / \mathrm{yr}$ inferred from the thermal

177 structure of the Nepal Himalaya for the past 10 m.y. (Bollinger et al., 2006; Herman et

178 al., 2010). Therefore, our observations indicate that a southward jump of the mid-crustal

179 ramp has taken place recently in Central Nepal $\left(83^{\circ} \mathrm{E}-86^{\circ} \mathrm{E}\right)$, adding support to the idea

180 that underplating, which is capable of maintaining the steep topography of the High

181 Himalaya on the long-term, is a discontinuous process in time. Resolving potential lateral

182 variations in the interseismic uplift pattern along the plate boundary is now required to 
understand how the segmentation of the MFT, which ultimately controls the size of great

184 Himalayan earthquakes, could be related to the underlying long-term evolution of the

185 MHT system.

\section{CONCLUSIONS}

Mountain growth in the Himalaya is to a large extent controlled by the presence of a mid-crustal ramp within the Main Himalayan Thrust system. Interseismic InSAR measurements indicate that the ramp is locked during the interseismic intervals, causing transient surface uplift above the transition zone. Over a large number of seismic cycles,

191 the flat-ramp-flat shape of the plate interface is expected to induce permanent uplift

192 above the ramp, whose surface expression is subdued by erosion, but which is

193 responsible for prominent topographic slopes and steep river profiles across the High

194 Himalaya. However, on the longer term, damage in the vicinity of the ramp produces

195 occasional brittle failure within the Indian plate that may bypass the MHT and lead to an

196 apparent southward migration of the mid-crustal ramp. Delayed erosional response to

197 such episodes of frontward ramp jump can produce the observed coincidence between the

198 peak of interseismic uplift detected by geodesy, and the peak of permanent uplift deduced

199 from riverbed morphology, which could not be otherwise explained by a steady-state

200 model of mountain growth.

\section{ACKNOWLEDGMENTS}

ENVISAT data was provided through European Space Agency’s (ESA)

203 program Dragon-2. The seismic catalog was provided by National Seismological

204 Centre (NSC) of Nepal. Interferometric processing partly relies on the ROI_PAC

205 software (Rosen et al., 2004). Post-doctoral fellowship for Grandin was provided by 
Publisher: GSA

Journal: GEOL: Geology

Article ID: G33154

French Centre National des Etudes Spatiales (CNES). We acknowledge funding from Institut National des Sciences de l'Univers (CT-Risk), ESA's Young Scientist Program and Agence Nationale de la Recherche (ANR) via project EFIDIR (ANR07-MDCO-004). This project was carried out within the frame of the joint ENS-CEA laboratory "LRC Yves Rocard”. We thank reviewers Roger Bilham, Roland Bürgmann, and Tim J. Wright, and Editor Sandra J. Wyld for their useful comments.

\section{REFERENCES CITED}

Banerjee, P., Bürgmann, R., Nagarajan, B., and Apel, E., 2008, Intraplate deformation of the Indian subcontinent: Geophysical Research Letters, v. 35, no. 18, p. L18301, doi:10.1029/2008GL035468.

Bettinelli, P., Avouac, J.-P., Flouzat, M., Jouanne, F., Bollinger, L., Willis, P., and Chitrakar, G.R., 2006, Plate motion of India and interseismic strain in the Nepal Himalaya from GPS and DORIS measurements: Journal of Geodesy, v. 80, no. 8-11, p. 567-589, doi:10.1007/s00190-006-0030-3.

Bilham, R. and 24 authors, 1997, GPS measurements of present-day convergence across the Nepal Himalaya: Nature, v. 386, no. 6620, p. 61-64, doi:10.1038/386061a0.

Bollinger, L., Henry, P., and Avouac, J.P., 2006, Mountain building in the Nepal Himalaya: Thermal and kinematic model: Earth and Planetary Science Letters, v. 244, no. 1-2, p. 58-71, doi:10.1016/j.eps1.2006.01.045.

Burbank, D.W., Blythe, A.E., Putkonen, J., Pratt-Sitaula, B., Gabet, E., Oskin, M., Barros, A., and Ojha, T.P., 2003, Decoupling of erosion and precipitation in the Himalayas: Nature, v. 426, no. 6967, p. 652-655, doi:10.1038/nature02187. 
Publisher: GSA

Journal: GEOL: Geology

Article ID: G33154

Cattin, R., and Avouac, J.-P., 2000, Modeling mountain building and the seismic cycle in the Himalaya of Nepal: Journal of Geophysical Research, v. 105, no. B6, p. 13389 13407, doi:10.1029/2000JB900032.

Doin, M.-P., Guillaso, S., Jolivet, R., Lasserre, C., Lodge, F., Ducret, G., and Grandin, R., 2011, Presentation of the small-baseline NSBAS processing chain on a case example: The Etna deformation monitoring from 2003 to 2010 using ENVISAT data: Proceedings of the European Space Agency Symposium « Fringe », Frascati, Italy.

Ducret, G., Doin, M.-P., Grandin, R., Lasserre, C., and Guillaso, S., 2011, DEM corrections before unwrapping in a small baseline strategy for insar time series analysis: Proceedings of the IEEE International Geoscience and Remote Sensing Symposium, Vancouver, Canada. (http://www.ustream.tv/recorded/16259302) (last accessed 25 April 2012).

Feldl, N., and Bilham, R., 2006, Great Himalayan earthquakes and the Tibetan plateau: Nature, v. 444, no. 7116, p. 165-170, doi:10.1038/nature05199.

Herman, F., Copeland, P., Avouac, J.-P., Bollinger, L., Mahéo, G., Le Fort, P., Rai, Foster, D., Pêcher, A., Stüwe, K. and Henry, P., 2010, Exhumation, crustal deformation, and thermal structure of the Nepal Himalaya derived from the inversion of thermochronological and thermobarometric data and modeling of the topography: Journal of Geophysical Research, v. 115, p. B06407, doi:10.1029/2008JB006126.

Hodges, K.V., Wobus, C., Ruhl, K., Schildgen, T., and Whipple, K., 2004, Quaternary deformation, river steepening, and heavy precipitation at the front of the Higher Himalayan ranges: Earth and Planetary Science Letters, v. 220, p. 379-389, doi:10.1016/S0012-821X(04)00063-9. 
Publisher: GSA

Journal: GEOL: Geology Article ID: G33154

Jackson, M., and Bilham, R., 1994, Constraints on Himalayan deformation inferred from vertical velocity fields in Nepal and Tibet: Journal of Geophysical Research, v. 99, no. B7, p. 13897-13912, doi:10.1029/94JB00714.

Jolivet, R., Grandin, R., Lasserre, C., Doin, M.-P., and Peltzer, G., 2011, Systematic InSAR tropospheric phase delay corrections from global meteorological reanalysis data: Geophysical Research Letters, v. 38, p. L17311, doi:10.1029/2011GL048757.

Lavé, J., and Avouac, J.P., 2001, Fluvial incision and tectonic uplift across the Himalayas of central Nepal: Journal of Geophysical Research, v. 106, no. B11, p. 26561-26591, doi:10.1029/2001JB000359.

Meade, B.J., 2010, The signature of an unbalanced earthquake cycle in Himalayan topography?: Geology, v. 38, no. 11, p. 987-990, doi:10.1130/G31439.1.

Nábělek, J., Hetényi, G., Vergne, J., Sapkota, S., Kafle, B., Jiang, M., Su, H., Chen, J., and Huang, B.-S., and the Hi-CLIMB Team, 2009, Underplating in the HimalayaTibet collision zone revealed by the Hi-CLIMB Experiment: Science, v. 325, no. 5946, p. 1371-1374, doi:10.1126/science.1167719.

Okada, Y., 1985, Surface deformation due to shear and tensile faults in a half-space: Bulletin of the Seismological Society of America, v. 75, no. 4, p. 1135-1154.

Pandey, M.R., Tandukar, R.P., Avouac, J.P., Lave, J., and Massot, J.P., 1995, Interseismic strain accumulation on the Himalayan Crustal Ramp (Nepal): Geophysical Research Letters, v. 22, no. 7, p. 751-754, doi:10.1029/94GL02971.

Pinel-Puysségur, B., Michel, R., and Avouac, J.-P., 2011, Multi-link SAR interferograms: Enhancement of a wrapped interferometric database: Proceedings of the IEEE International Geoscience and Remote Sensing Symposium, Vancouver, Canada. 
Publisher: GSA

Journal: GEOL: Geology

Article ID: G33154

Robinson, D.M., DeCelles, P.G., Garzione, C.N., Pearson, O.N., Harrison, T.M., and Catlos, E.J., 2003, Kinematic model for the Main Central thrust in Nepal: Geology, v. 31, p. 359-362, doi:10.1130/0091-7613(2003)031<0359:KMFTMC>2.0.CO;2.

Rosen, P.A., Henley, S., Peltzer, G., and Simons, M., 2004, Updated repeat orbit interferometry package released: Eos [Transactions, American Geophysical Union], v. 85, p. 47 .

Schelling, D., 1992, The tectonostratigraphy and structure of the eastern Nepal Himalaya: Tectonics, v. 11, no. 5, p. 925-943, doi:10.1029/92TC00213.

Seeber, L., and Gornitz, V., 1983, River profiles along the Himalayan arc as indicators of active tectonics: Tectonophysics, v. 92, no. 4, p. 335-367, doi:10.1016/00401951(83)90201-9.

Socquet, A., Vigny, C., Chamot-Rooke, N., Simons, W., Rangin, C., and Ambrosius, B., 2006, India and Sunda plates motion and deformation along their boundary in Myanmar determined by GPS: Journal of Geophysical Research, v. 111, no. B5, p. B05406, doi:10.1029/2005JB003877.

Tarantola, A., and Valette, B., 1982, Generalized nonlinear inverse problems solved using the least squares criterion: Reviews of Geophysics and Space Physics, v. 20, p. 219, doi:10.1029/RG020i002p00219.

Vergne, J., Cattin, R., and Avouac, J.P., 2001, On the use of dislocations to model interseismic strain and stress build-up at intracontinental thrust faults: Geophysical Journal International, v. 147, no. 1, p. 155-162, doi:10.1046/j.1365246X.2001.00524.X. 
312 Figure 2. Geometry of the MHT. Upper panel: profiles perpendicular to the mountain
Wobus, C., Heimsath, A., Whipple, K., and Hodges, K., 2005, Active out-of-sequence thrust faulting in the central Nepalese Himalaya: Nature, v. 434, no. 7036, p. 1008 1011, doi:10.1038/nature03499.

\section{FIGURE CAPTIONS}

Figure 1. Vertical interseismic uplift in Central Nepal. Map of Central Nepal showing the main faults related to shortening across the Himalaya. MCT-Main Central Thrust; MBT_-Main Boundary Thrust; MFT_Main Frontal Thrust. The three branches merge at depth with the Main Himalayan Thrust (MHT) dipping north under Tibet. Interferometric synthetic aperture radar (InSAR) and leveling (Jackson and Bilham, 1994) measurements of the vertical velocity are color coded from blue (subsidence) to red (uplift). White circles represent the microseismic activity between 2000 and 2008 recorded by the National Seismological Centre of Nepal. Small and large white triangles indicate the location of the peaks with elevation above $7200 \mathrm{~m}$ and $8000 \mathrm{~m}$, respectively $(\mathrm{A}-$ Annapurna ; D—Dhaulagiri; $\mathrm{M}$-Manaslu; X-Xishapangma). $\mathrm{PT}_{2}$ - physiographic transition 2 (from Wobus et al. 2005).

313 range in West- (left) and East-Central Nepal (right) showing the horizontal velocities

314 derived from GPS and the vertical velocities derived from interferometric synthetic 315 aperture radar (InSAR) and leveling. Geodetic data have been projected along the profiles

316 indicated in Figure 1. Error bars denote 1 uncertainties on GPS velocities. Uncertainties 317 on leveling and InSAR are $0.2-2.8 \mathrm{~mm} / \mathrm{yr}$ and $0.7-3.1 \mathrm{~mm} / \mathrm{yr}$, respectively. Colored 318 curves correspond to modeled interseismic deformation using a buried fault model. West- 
Nepal (green): $\operatorname{dip}=7.4^{\circ} ; \operatorname{depth}=24.2 \mathrm{~km} ;$ slip rate $=19.6 \mathrm{~mm} / \mathrm{yr}$. The modeled

deformation in West-Central Nepal has been duplicated on the right panel for comparison

322 (dashed red line). Middle panel: stack of six denudation profiles determined from a study

of river incision (black line, Lavé and Avouac, 2001). Note that the same vertical scale is

used to represent interseismic uplift and denudation rates. The average topographic

325

profile is indicated in gray, with the envelope showing the minimum and maximum

326

elevations in an $\sim 100-\mathrm{km}$-wide box centered on the main profiles. Lower panel: geometry

of the two inverted dislocations (red and green lines) represented on typical cross sections

showing the main faults at depth (STD — South Tibetan Detachment; ITSZ — Indus

Tsangpo Suture Zone) (Lavé and Avouac, 2001). The blue histogram shows the

330

distribution of seismic activity along the profile. Vertical exaggeration in the lower panel

331 is $2 \times$.

332

333 Figure 3. Seismic cycle, topographic construction and long-term evolution of the

334 MHT. Three models showing the possible spatial relationship between interseismic uplift

335 profile (green curve at the top), long-term uplift profile (black curve at the top) and

336 microseismicity (blue histogram at the top) as a function of the underlying processes

337 taking place within the seismogenic crust.

338

$339{ }^{1}$ GSA Data Repository item 2012xxx, details of the InSAR processing scheme and

340 inversion procedure, is available online at www.geosociety.org/pubs/ft2012.htm, or on 
Publisher: GSA

341 request from editing@geosociety.org or Documents Secretary, GSA, P.O. Box 9140,

342 Boulder, CO 80301, USA. 
Figure 1

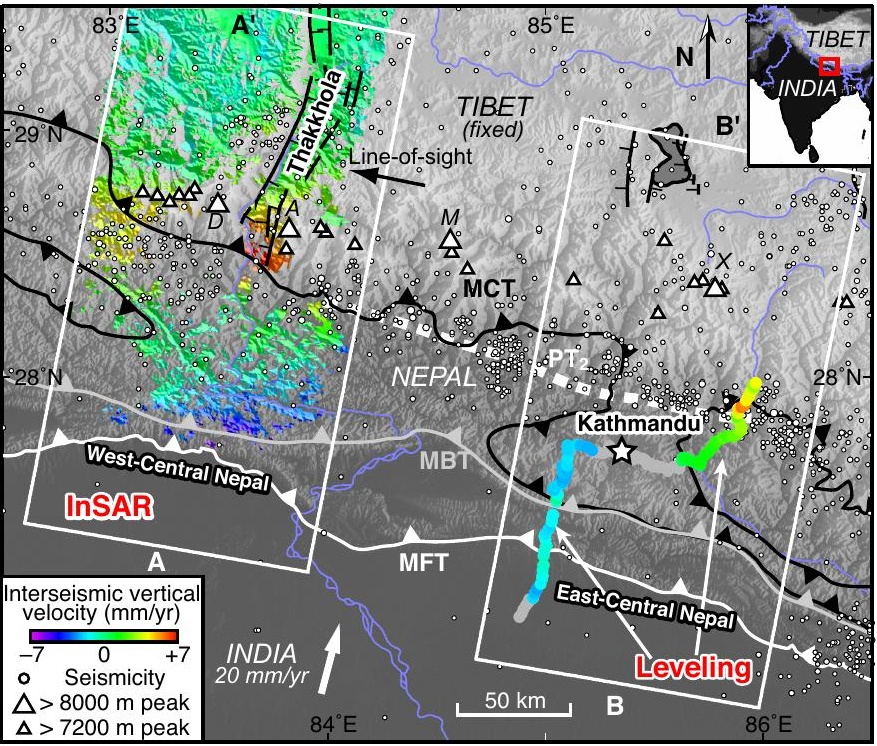


Figure 2
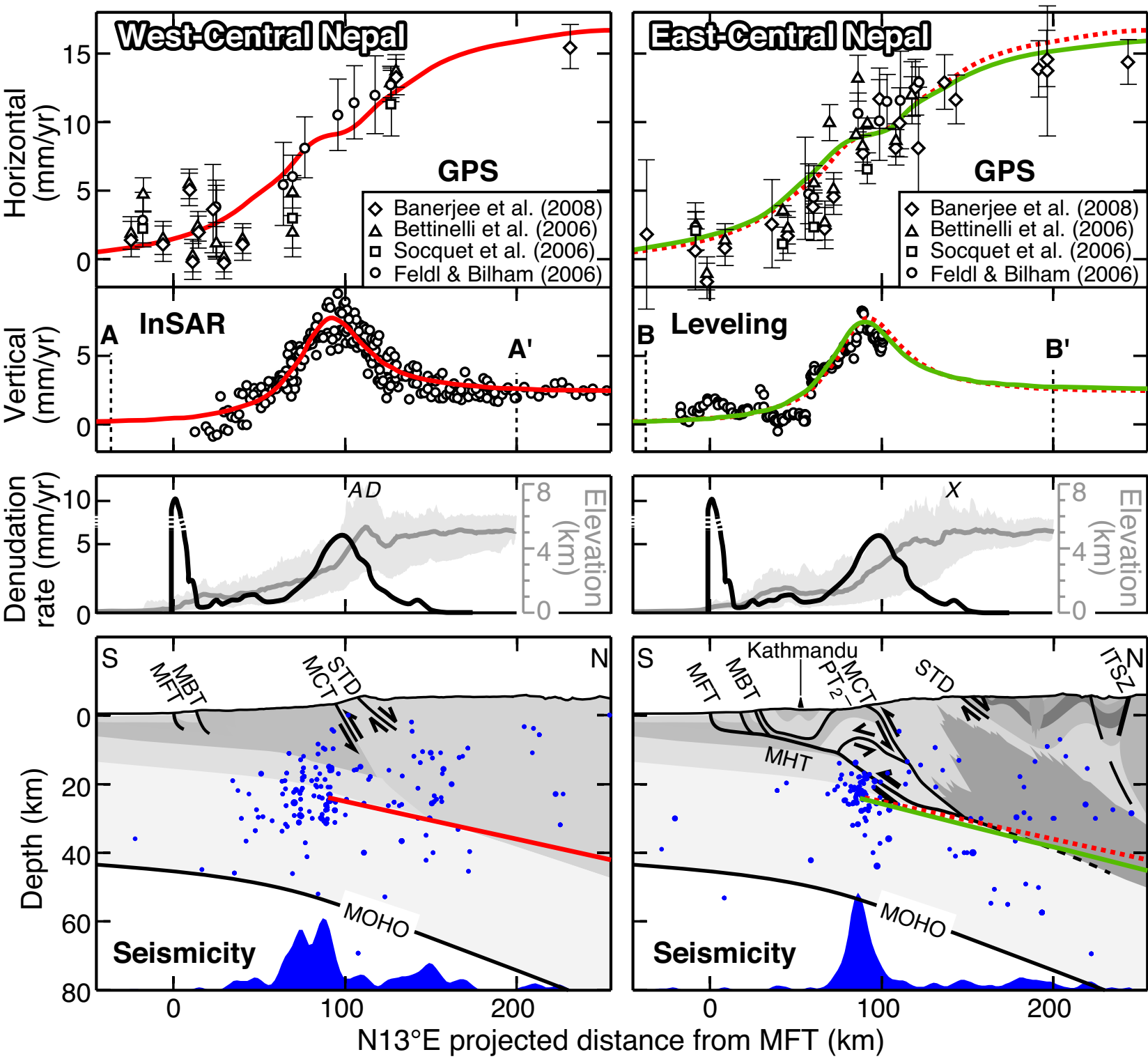
Figure 3

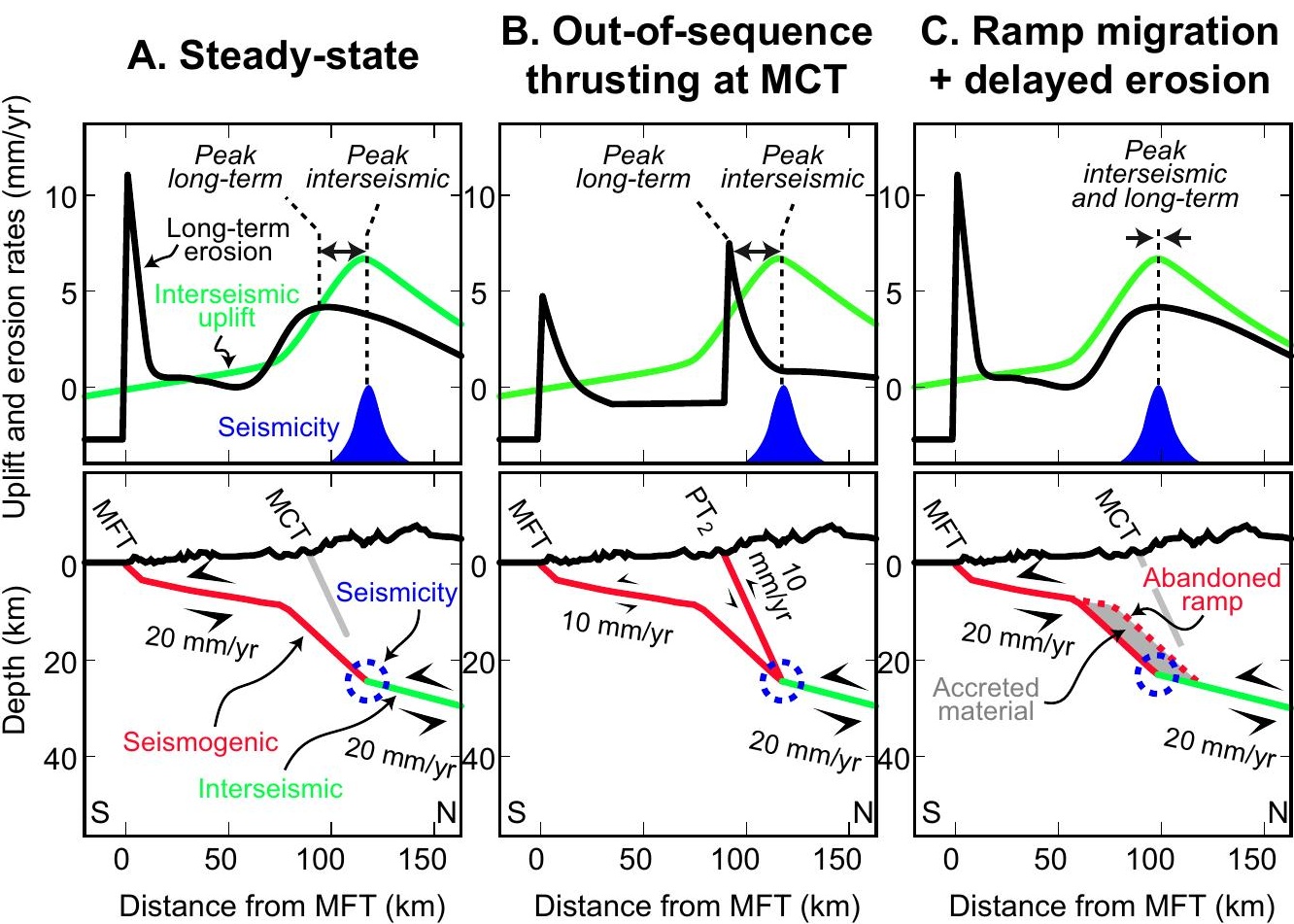




\title{
"Long-term growth of the Himalaya inferred from interseismic InSAR measurement"
}

\author{
R. Grandin, M.-P. Doin, L. Bollinger, B. Pinel-Puysségur, \\ G. Ducret, R. Jolivet and S. N. Sapkota,
}

published in Geology

Supplementary information

\section{Interferometric Synthetic Aperture Radar (InSAR) processing}

The main difficulty opposed to InSAR studies in the Himalaya is the poor coherence of the area. A common method to enhance the coherence is interferogram multi-looking. However, the combination of a rough topography and strong seasonality in the Himalaya induces large spatial and temporal variations of the tropospheric stratified delay, often producing tightly separated fringes that follow elevation contours in the interferograms [Jolivet et al., 2011]. These fringes can be aliased if multi-looking is applied to the interferograms. This results in complete coherence loss, contrary to the desired effect of multi-looking. Previous attempts to measure ground deformation with InSAR in this region, which did not have a specific strategy to remove troposphere-related fringes prior to phase unwrapping, have encountered that problem.

In addition, other sources of errors should be corrected prior to unwrapping. These include digital elevation model (DEM) errors and phase noise. These perturbations can be handled using numerous SAR acquisitions, which is now possible thanks to the extensive ENVISAT archive accumulated since 2002, and the

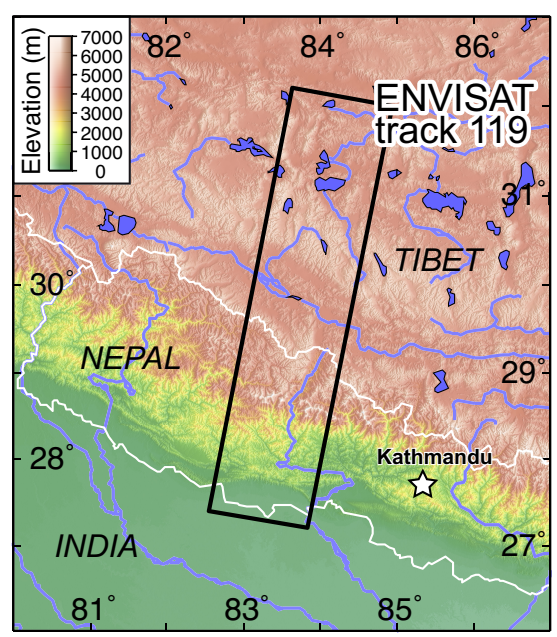

Figure S-1: Map showing the swath covered by ENVISAT track 119 used in this study. systematic acquisitions performed since 2008 in the Himalaya-Tibet area within the framework of European Space Agency's (ESA) Dragon program. Finally, the rough topography

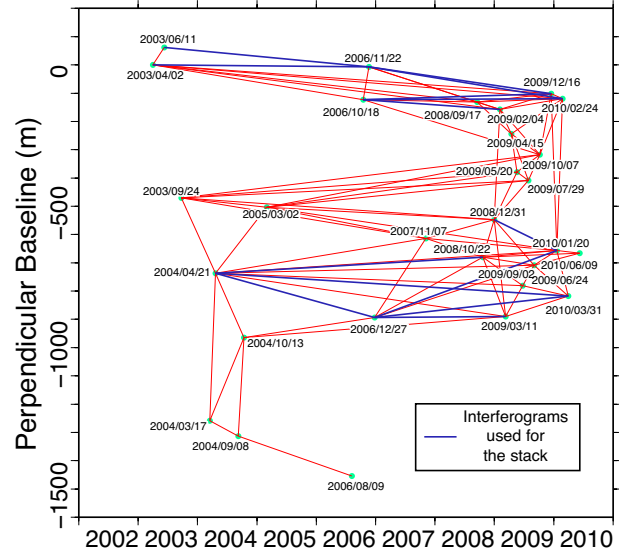

Figure S-2: Dates of image acquisitions as a function of perpendicular baseline. Red segments show the interferograms that have been calculated, among which blue segments show the interferograms used for the stack. precise pixel matching among the different interferograms formed from the coregistrated SLCs. Here, 

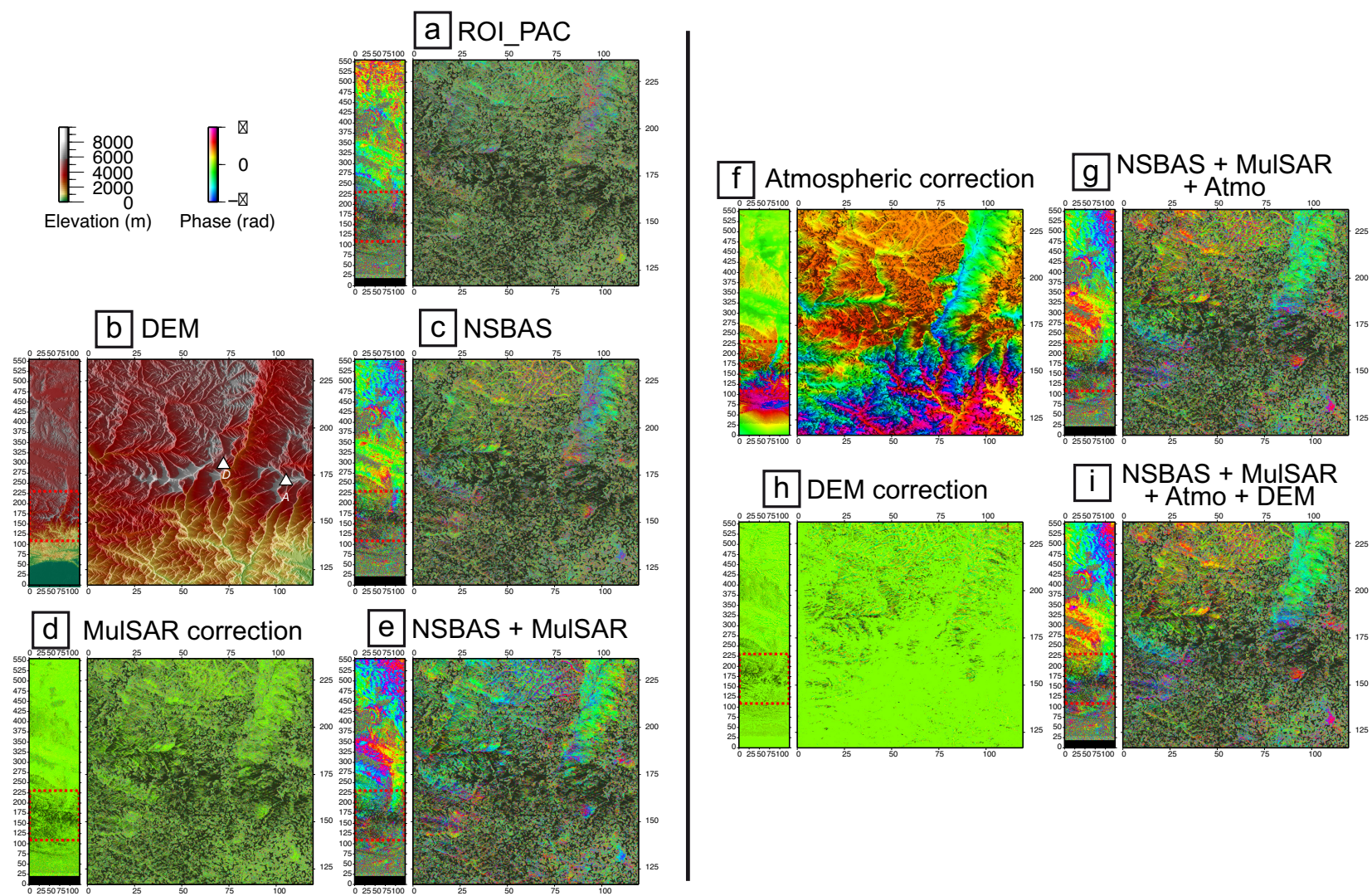

NSBAS + MulSAR

+ Atmo + DEM

Figure S-3: Example of the effect of successive corrections applied prior to phase unwrapping. The example corresponds to an interferogram between $2006 / 12 / 27$ and $2010 / 01 / 20$ which was used in the stack. The temporal baseline of the interferogram is 3.06 years, and its perpendicular baseline is $236 \mathrm{~m}$, which correspond to unfavourable conditions in terms of interferometric coherence. For each step, in order to highlight the impact of corrections on a broad scale and on a small scale, the interferogram spanning the whole swath (see Figure S-1 for location) is shown to the left of a blow up on the area with greatest topographic relief centered on the Himalaya (area surrounded by red dashed box). Areas in black in interferograms are incoherent regions where corrections are inefficient. (a) Interferogram processed with ROI_PAC. (b) SRTM-DEM in radar geometry. A: Annapurna. D: Dhaulagiri. (c) Interferogram processed with NSBAS $\bar{D}$ Doin et al., 2011]. (d) Correction for this interferogram determined after Multi-link InSAR time series (MulSAR) processing [Pinel-Puysségur et al., 2011]. (e) Interferogram after MulSAR correction. (f) Tropospheric delay correction computed from the ERA-Interim atmospheric model [Jolivet et al., 2011]. (g) Interferogram after atmospheric correction. (h) DEM correction calculated from combination of (wrapped) coherent interferograms with large perpendicular baselines and small temporal baselines [Ducret et al., 2011]. (i) Interferogram after DEM correction. Note the substantial improvement of the coherence between (a) and (i).

we used orbits derived from the onboard DORIS sensor [Zandbergen et al., 2003]. For the DEM, Version 4 of Shuttle Radar Topographic Mission Digital Elevation Model (SRTM-DEM-V4 [Farr et al., 2007]) was chosen because holes corresponding to the main Himalayan glaciers in previous versions of SRTM have been filled using regular topographic maps (data courtesy of Jonathan de Ferranti ${ }^{1}$ ). In addition, a slope adaptive spectral shift range filtering was applied during interferogram formation to reduce geometric decorrelation caused by steep terrain slopes in the study area (implemented by S. Guillaso, following [Gatelli et al., 1994; Davidson and Bamler, 1999]). From the 29 co-registered SLCs, we computed 98 interferograms that allow for a fully connected interferometric network (Figure S-2). Calculated pairs include interferograms with a large temporal baseline (of direct interest for the measurement of interseismic deformation) but also images with a small temporal baseline and large perpendicular baseline (mainly used to connect between sets of images and to determine the DEM correction).

A series of cascading corrections were performed using the 4-look wrapped interferograms (i.e. 20-look in azimuth, 4-look in range) in order to enhance the coherence and reduce the risk of phase aliasing during the subsequent processing steps of multi-looking and phase unwrapping. An example interferogram with a large temporal baseline (3.06 years) and a large perpendicular baseline $(236 \mathrm{~m})$ is shown in Figure S-3 to highlight the impact of these successive corrections. All wrapped interfero-

${ }^{1}$ http://www.viewfinderpanoramas.org/dem3.html\#himalayas, last accessed 25 April 2012 
grams were re-processed using the Multi-link InSAR time series scheme (MulSAR), which exploits the redundant information on the pixel phase by combining all the alternative paths between the master and slave image in the interferometric network, within the limit of three interferograms per path [PinelPuysségur et al., 2011] (Figure S-3 d-e). The resulting interferograms were then corrected from the effect of space-time variations of the stratified tropospheric component using the European Centre for Medium Range Weather Forecast (ECMWF) ERA-Interim meteorological reanalysis (Figure S-3 f-g). The method is described in detail in [Jolivet et al., 2011]. We note that the atmospheric correction provides the most important improvement; as it limits the aliasing of tightly separated topographycorrelated fringes on the slopes of Himalaya in the later multi-looking step. Finally, DEM errors were calculated pixelwise by a non-linear inversion of the regression between perpendicular baseline and the (wrapped) interferometric phase, using the method of [Ducret et al., 2011] (Figure S-3 h-i). A subset of 36 interferograms with strong perpendicular baseline, small temporal baseline and good coherence
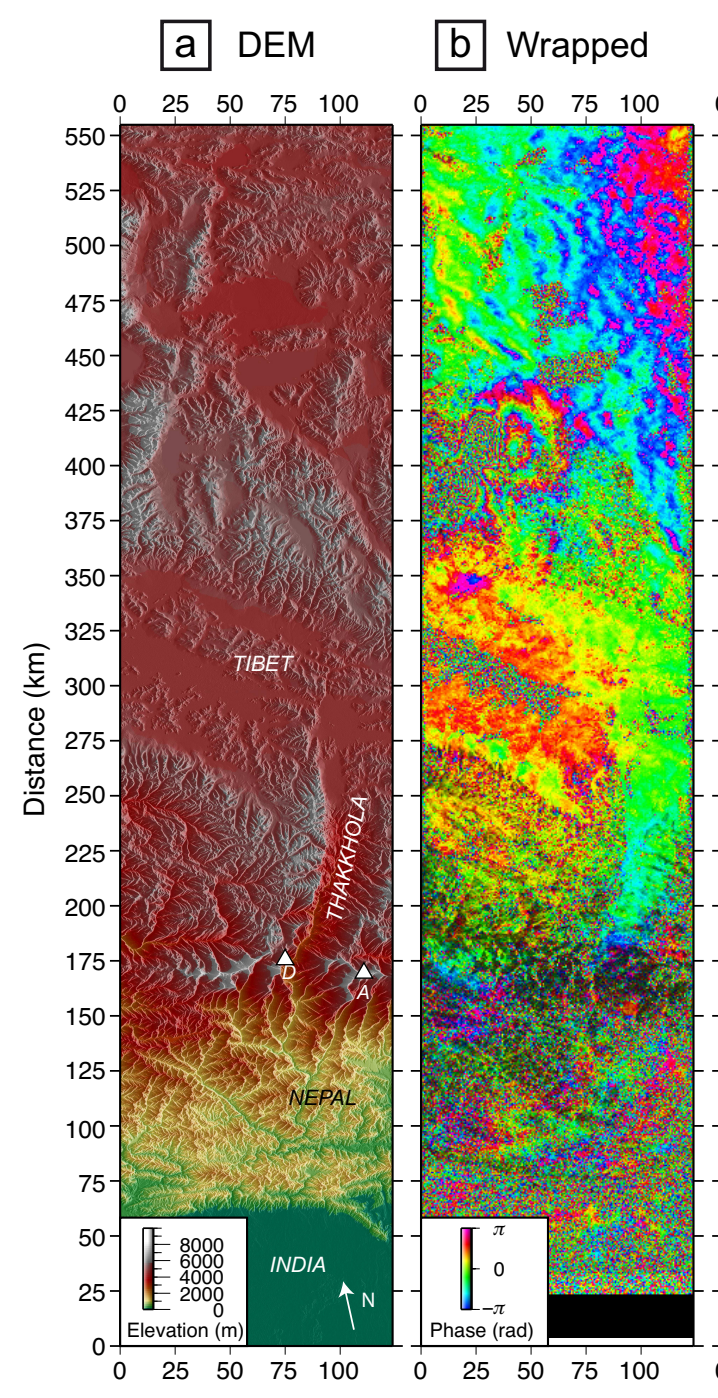
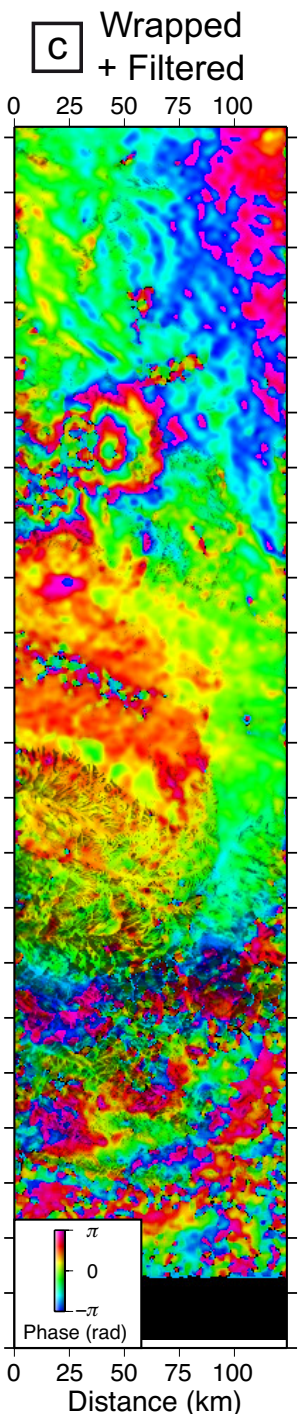

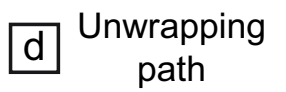

$\begin{array}{lllll}0 & 25 & 50 & 75 & 100\end{array}$

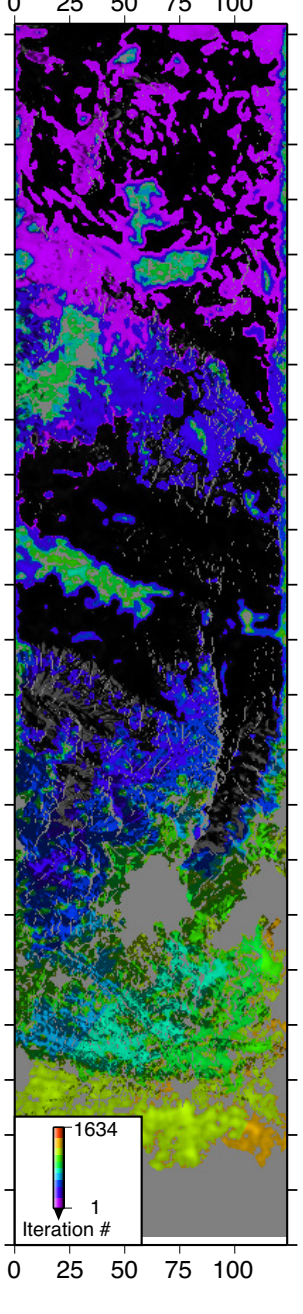

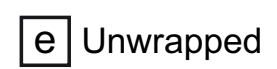

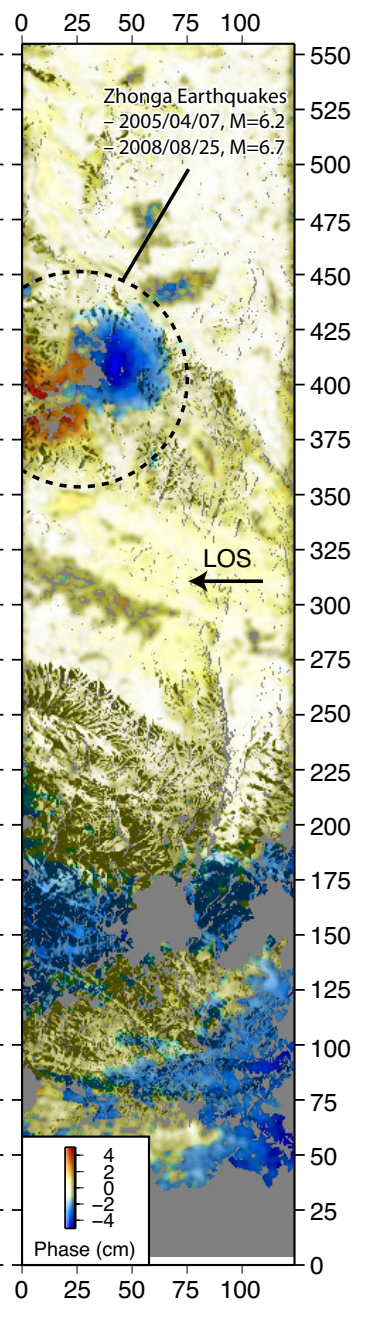

Figure S-4: Example of the process of filtering and unwrapping. The interferogram chosen for this example is the same as in Figure S-3. Areas in black are incoherent regions. (a) SRTM-DEM in radar geometry. (b) Wrapped interferogram after application of successive corrections aimed at enhancing the coherence (see Figure S-3). (c) Filtered, wrapped interferogram. (d) Unwrapping paths taken to propagate the unwrapping seed throughout the whole image during successive iterations corresponding to decreasing coherence thresholds. (e) Unwrapped interferogram. Unwrapping starts in areas coloured in black in (d), which correspond to areas of maximum coherence. Unwrapping then propagates toward regions of lower coherence, first in Tibet, then along the slopes of the Himalaya down to Nepal and India (bottom of the image). Two distinct unwrapping paths are found to cross the Himalaya: (1) along the western border of the image, and (2) along the Thakkhola graben between Dhaulagiri (D) and Annapurna (A). These two unwrapping paths merge in the Southern Thakkhola graben. No phase jump can be noticed at the junction of the two paths (e), indicating that unwrapping is not affected by large scale errors. In the upper part of the image, coseismic deformation associated with two earthquakes in 2005 and 2008 is also visible. 


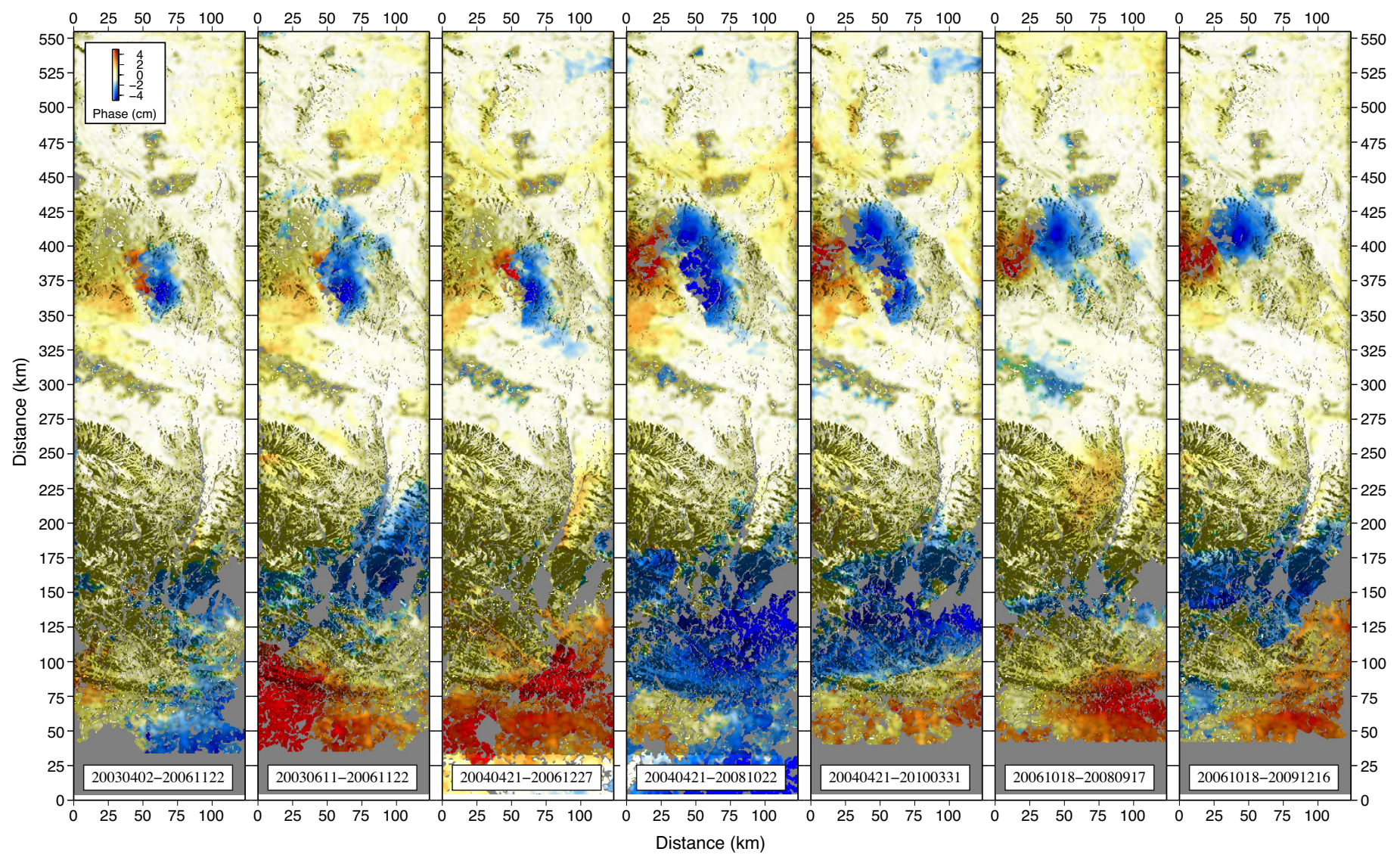

Figure S-5: Seven unwrapped interferograms among the 14 interferograms used in the stack. Interferograms are sorted as a function of the date of the first acquisition.

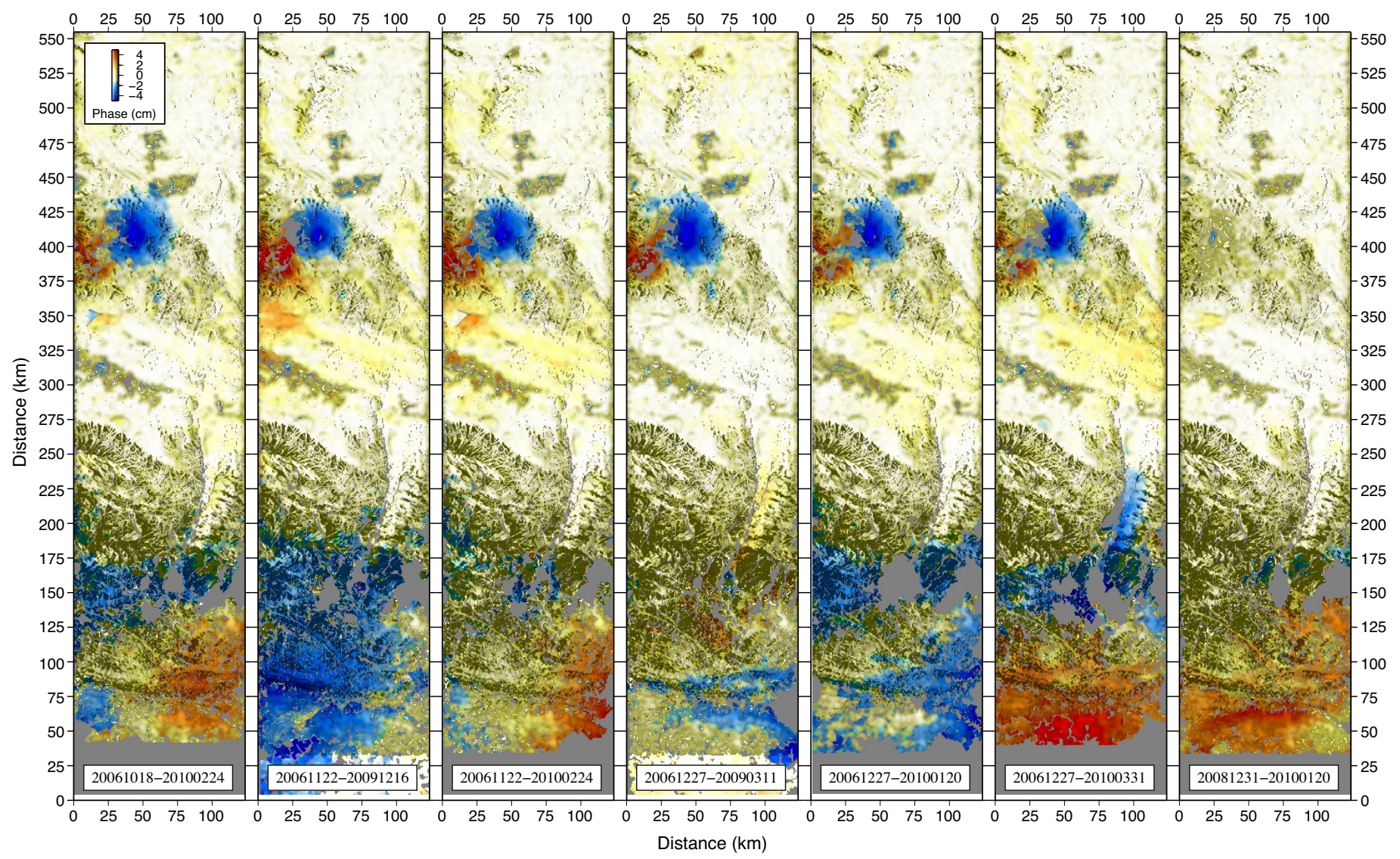

Figure S-6: Same as Figure S-5, for the seven remaining interferograms. 

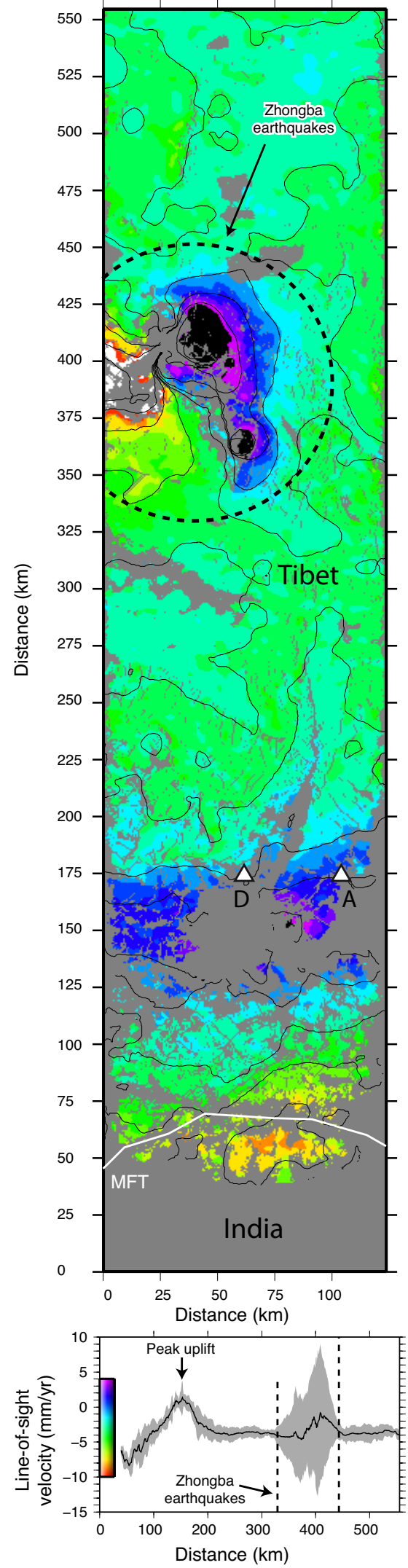

Figure S-7: $\quad$ Stack obtained by summation of unwrapped interferograms of Figures S-5 and S-6. Note that the average velocity has been calculated from pixels that have been correctly unwrapped for all 14 interferograms. Bottom panel shows a cross-section for a profile crossing the image along the satellite heading direction (azimuth direction), with the black curve corresponding to average line-of-sight velocity on each line, and the grey envelope showing $1 \sigma$ standard deviation. were used to determine the DEM error map, and the correction was subsequently applied to all other interferograms in the data set using their respective perpendicular baselines.

After these corrections, the resulting wrapped interferograms were multi-looked by an additional factor of 8 (i.e. leading to 32-look). Figure S-4 shows the unwrapping process applied to the example 32-look interferogram. To reduce phase noise, a 4 -pixel wide triangular filter was applied to the wrapped 32-look interferograms, which represents a $\sim 2.5 \mathrm{~km}$-wide averaging kernel (Figure S-4 b-c).

Unwrapping is achieved in an iterative manner, using coherence as a criterion to determine an optimal unwrapping path (Figure S-4 d-e). The coherence used for unwrapping has been previously calculated in the same 4-pixel wide regions used for phase filtering. First, unwrapping is performed in the sub-region of the interferogram where coherence is maximum (i.e. with coherence above a certain threshold). At each iteration, the coherence threshold is slightly decreased, and unwrapping is propagated into the contiguous areas where coherence is above the new threshold. The threshold is progressively decreased to expand unwrapping toward regions of lower coherence at each iteration. Regions with a coherence below a minimum threshold are not unwrapped, as the phase is considered unreliable there. In addition, regions of spectral layover are assigned a very low coherence, and therefore behave as barriers that cannot be crossed during phase unwrapping (cuts). At each step, the unwrapping seed is propagated towards the region with the highest coherence, in order to favor unwrapping along the most coherent paths. Compared to cut-tree algorithm, our method accounts for the hierarchy in terms of phase reliability between regions with different levels of coherence. For example, our scheme tends to propagate unwrapping along coherent river valleys, and to avoid unwrapping to cross incoherent snow-capped mountain ridges which are unwrapped at the end of the process. The resulting interferograms are correctly unwrapped in the highly coherent region of the interferograms corresponding to Tibet, but errors tend to increase as unwrapping is propagated towards the South in Nepal. Coherence is smallest near the latitude of the high Himalaya, and is relatively higher to the South in the sub-Himalaya. Two separated unwrapping paths are usually found to connect Tibet and the sub-Himalaya: along the Thakkhola graben to the East of the track, and West of the Dhaulagiri Himal on the other side of the track (Figure S-4d). This makes possible to perform an aposteriori check of the unwrapping reliability: if no phase jump is observed across either of the two low-coherence bottlenecks near the High Himalaya, then we can conclude that unwrapping has been achieved without producing a large-scale error. As a final step, unwrapped interferograms are geocoded.

Due to the overall poor coherence in the Himalaya, especially when the perpendicular baseline is high, only a small number of interferograms could be successfully unwrapped across the mountain range. Therefore, advanced post-processing techniques such as "small baseline" could not be applied to monitor time variations of the deformation. Instead, a simple stacking approach was adopted to highlight an average interseismic velocity map. We 
selected a subset of 14 successfully unwrapped interferograms (including the contribution of 14 distinct images) that combine a large temporal baseline, a reasonably good coherence, and a reliable phase unwrapping (Figure S-2). These interferograms are shown in Figures S-5 and S-6. The interferograms were summed, and the result was divided by the total time spanned by the subset of interferograms (45 years in our case) in order to yield a line-of-sight (LOS) velocity map (Figure S-7). To compute the average velocity map, we chose a conservative approach by restricting the calculation to regions where all 14 interferograms have been successfully unwrapped. A "jackknife" analysis shows that the resulting velocity map is nearly insensitive to the exclusion of any interferogram among the list of 14 stacked interferograms.

We performed an error analysis to assess the amount of uncertainty affecting our final InSAR stack. For each interferogram used in the stack, we have computed semi-variograms of the residual LOS map after removal of the best-fit deformation model. Only the southern half of the InSAR swath was used, in order to highlight a noise level relevant to the area where interseismic deformation is observed (i.e. the Himalaya). The mean of the standard deviation of the interferograms at $50 \mathrm{~km}$ spatial wavelength (the
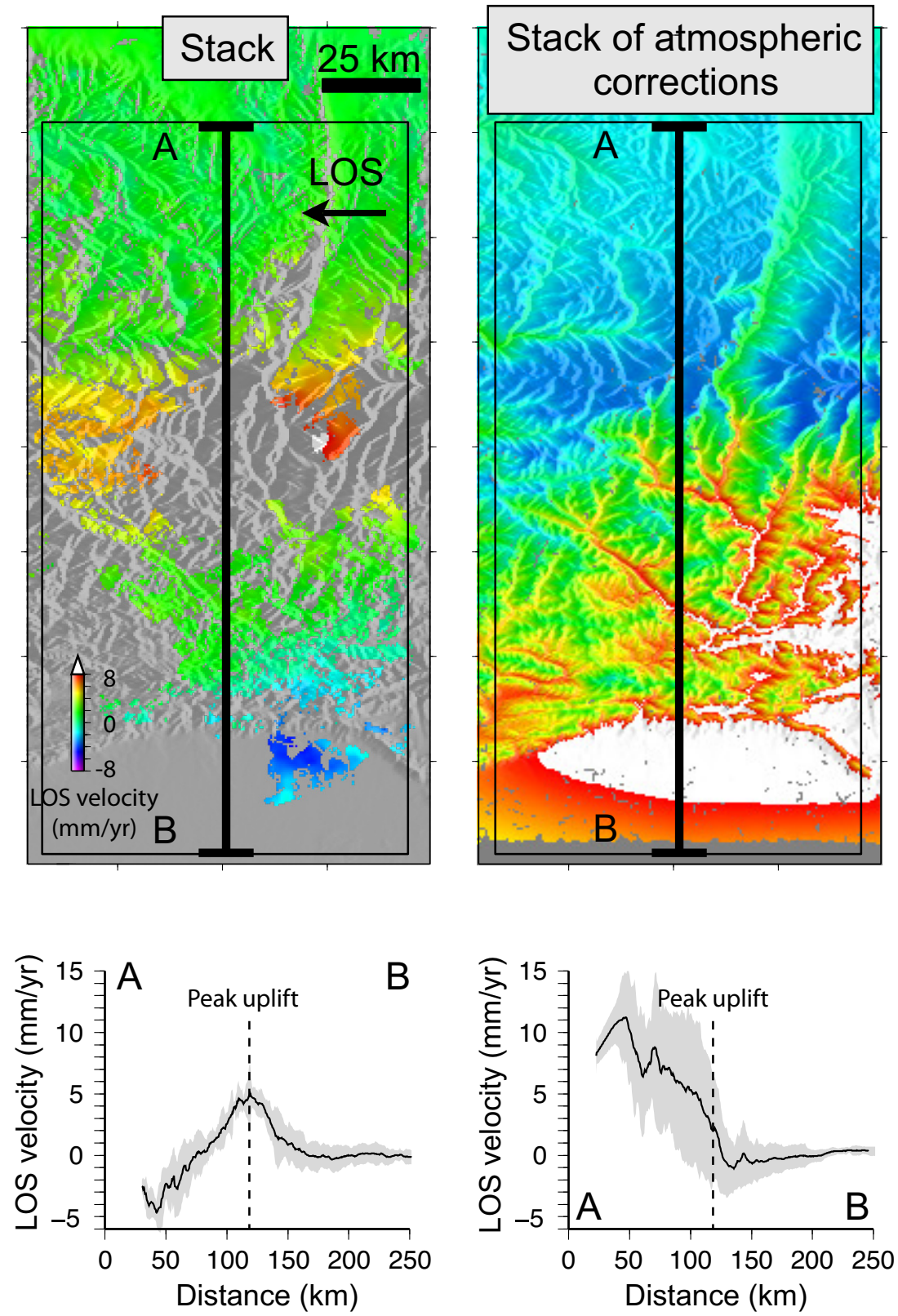

Figure S-8: Comparison between average LOS velocity map deduced from stack calculation (left) versus sum of the atmospheric corrections that have been subtracted from the 14 interferograms used to compute the stack (right). Bottom panel shows profiles along azimuth direction. The atmospheric correction is strongly correlated to elevation, whereas the retrieved LOS velocity map is unrelated to the distribution of elevations throughout the image, indicating that (1) the tropospheric delay contribution has been successfully removed from individual interferograms and (2) that the peak uplift obtained in the corrected stack was not introduced by inappropriate modeling of the tropospheric delay. 
spatial wavelength of the uplift peak imaged by InSAR) was used as the reference standard deviation of any interferogram in the stack: $\sigma_{\text {interf }}=21 \mathrm{~mm}$. From $\sigma_{\text {interf }}$, the average standard deviation of individual acquisitions $\sigma_{\text {acquis }}$ is deduced by assuming that the variance of each interferogram equals the sum of the variances of the slave and master acquisitions. Hence, $\sigma_{\text {acquis }}=\sigma_{\text {interf }} / \sqrt{2}=15 \mathrm{~mm}$. Finally, 10000 simulations of the noise in each acquisition were performed. Each acquisition was assumed to be the realization of a Gaussian random variable, with its mean equal to zero and its standard deviation equal to $\sigma_{\text {acquis }}$. The noise in the interferograms was then computed as the difference between the simulated noise amplitudes of slave and master acquisitions. The final noise amplitude in the average velocity map was calculated by reconstructing the stack (Figure S-2). The simulated noise in the stack was observed to follow a normal distribution centered at zero, with its standard deviation equal to $\sigma_{\text {stack }}=3.1 \mathrm{~mm} / \mathrm{yr}$. This compares to $\sigma_{\text {stack }}=2.5 \mathrm{~mm} / \mathrm{yr}$ if the stack were composed of 14 independent interferograms. Such a level of uncertainty is likely an overestimation, as the best model of deformation is capable of fitting the InSAR data to a level of $\sigma_{\text {residual }}=0.7 \mathrm{~mm} / \mathrm{yr}$ (Table T-1). We conclude that the uncertainty on the InSAR-derived velocity map lies in the range of $0.7-3.1 \mathrm{~mm} / \mathrm{yr}$.

The stack shows a region affected by motion toward the satellite with a peak located $\sim 25 \mathrm{~km}$ South of the summits of the High Himalaya (Figure S-7). This signal appears to be uncorrelated with any topographic feature, as shown in Figure S-8. Because the chosen ENVISAT track is oriented parallel to the direction of India/Tibet convergence (descending track), the LOS measurement is virtually insensitive to horizontal displacements related to shortening perpendicular to the Himalayan range. Therefore, the LOS velocity map is converted to a vertical velocity map by dividing by the cosine of the incidence angle (between $19^{\circ}$ for the near-range and $26^{\circ}$ for the far-range). The band of LOS velocity directed toward the satellite is interpreted as a direct measurement of uplift caused by interseismic contraction of rocks above the transition zone between the locked and free slipping portions of the Main Himalayan Thrust (MHT). The peak uplift velocity is approximately $5-7 \mathrm{~mm} / \mathrm{yr}$. The amplitude and wavelength of the signal are consistent with leveling measurements of interseismic uplift in the Kathmandu area [Jackson and Bilham, 1994]. Further to the South, moderate motion away from the satellite (possibly subsidence) is observed, but this signal is considered unreliable South of the MFT due to suspected unwrapping errors across the MFT. Therefore, InSAR data South of the MFT has not been used in the inversions. The stack also includes coseismic deformation associated with the Zhongba earthquakes of $11 / 07 / 2004(M=6.2), 07 / 04 / 2005(M=6.2)$ and $25 / 08 / 2008(M=6.7)$ in the Tibet interior (Figures S-3, S-5, S-6 and S-7). The average velocity in this area is therefore meaningless for the description of interseismic deformation, and has been clipped. Elsewhere in Tibet, the resulting velocity map shows no notable deformation. A bilinear phase ramp is adjusted in the region located North of $29^{\circ} \mathrm{N}$, and then subtracted to the whole InSAR stack, in order to reference the deformation with respect to a stable Tibetan plateau. The slight longitudinal difference in uplift velocities within the InSAR track could be interpreted as lateral variability of the underlying fault properties, with more interseismic coupling, a shallower locking depth below the eastern part of the track compared to the western part of the track, and/or extension within the Thakkhola graben. However, the difference in uplift velocity is within the uncertainty of the InSAR measurement $(\sim 2 \mathrm{~mm} / \mathrm{yr})$, and cannot be interpreted further. 


\section{Leveling data}

To complement InSAR measurement in West-Central Nepal, we also use spirit leveling measurements in the East-Central Nepal region (Kathmandu area) reported by Jackson and Bilham [1994] and originally measured by the Survey Department of Nepal since 1977 (Figure S-9). The leveling survey was performed along a $350 \mathrm{~km}$-long line, trending roughly North-South, and crossing the MFT, the MBT and the MCT. However, due to an east-west jog of nearly $60 \mathrm{~km}$ in the profile at the latitude of Kathmandu, the range-perpendicular coverage of the profile is only $130 \mathrm{~km}$. The leveling profile shows a gentle increase of the uplift rate toward the North, with a peak uplift reached $\sim 90 \mathrm{~km}$ North of the MFT. The lower part of the profile was revisited after an interval of 13 years, whereas the upper part of the profile spans 7 years of deformation, and only 2 years for the uppermost part of the profile, i.e. North of the peak uplift. Unfortunately, the profile ends only $10 \mathrm{~km}$ North of the peak uplift. In our analysis, outliers in the Kathmandu valley and lowlands have been removed, following Bettinelli et al. [2006].

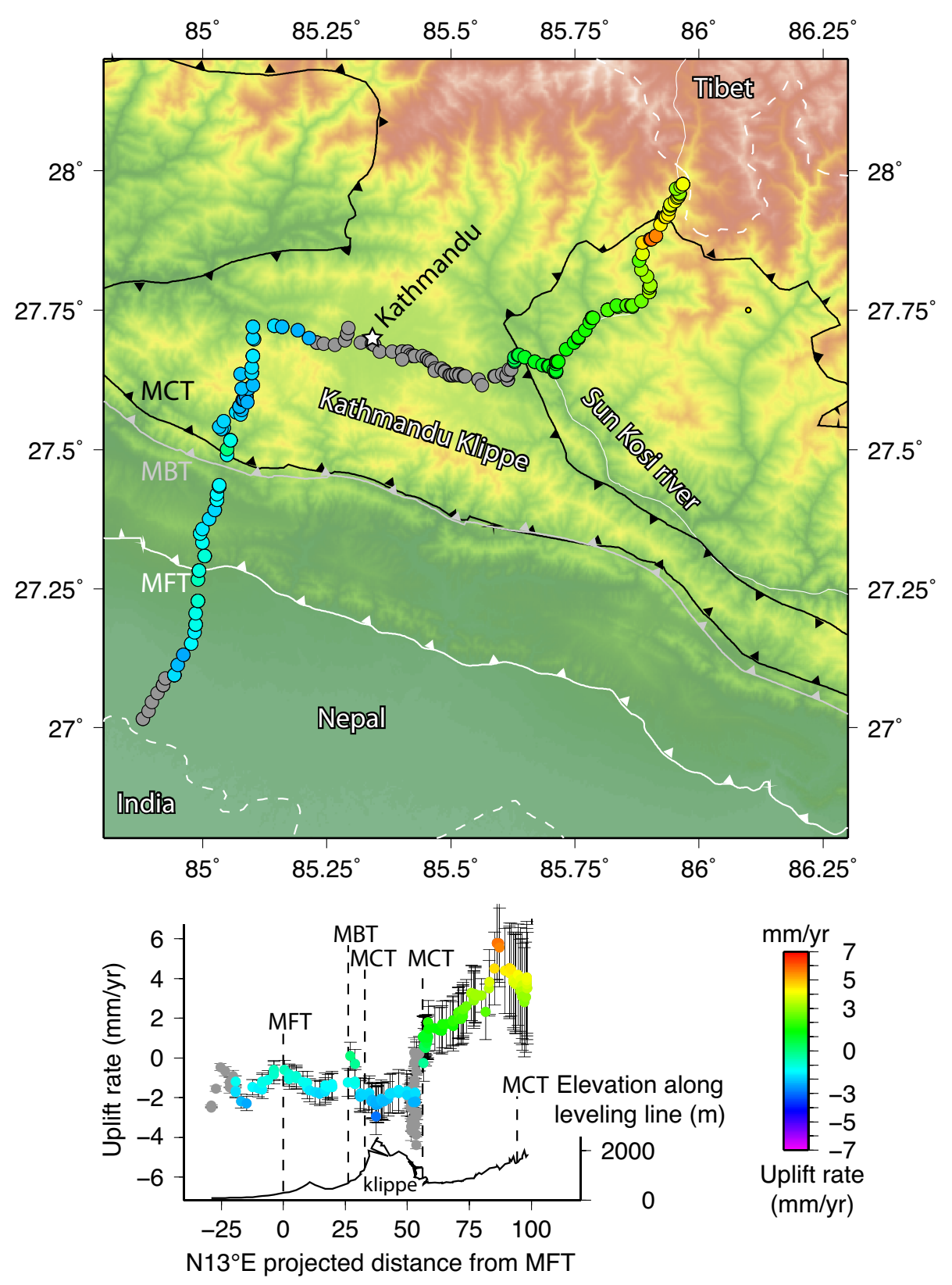

Figure S-9: Leveling data used in this study [Jackson and Bilham, 1994]. Top: map of the leveling profile overlaid on a DEM of the Kathmandu area. Vertical velocity is color coded from blue (subsidence) to red (uplift). Data points in grey correspond to measurements affected by subsidence in the Kathmandu valley that have been discarded from the inversion input. In its upper part, the profile follows the Sun Kosi river, which is indicated in grey. Bottom: vertical velocity along the leveling profile projected along a N13 ${ }^{\circ} \mathrm{E}$ direction, with the origin of the x-axis set to the MFT. Error bars correspond to $1 \sigma$ standard deviation uncertainties. Elevation along the leveling line is indicated below. 


\section{Global Positioning Sytem (GPS) data}

To constrain the horizontal component of the interseismic velocity field, we focus on four GPS data sets published by Bettinelli et al. [2006], Socquet et al. [2006], Feldl and Bilham [2006] and Banerjee et al. [2008]. These data sets provide a good spatial coverage of the region imaged by InSAR in West-Central Nepal, as well as dense coverage in the Kathmandu area in East-Central Nepal where the leveling line was measured. The data consist of a few continuous GPS stations operated since 1997 jointly by the Nepalese Department of Mines and Geology (DMG) and French CEA-DASE in the Kathmandu area. However, most GPS measurements were carried out during campaign surveys by teams of the Cooperative Institute for Research in Environmental Sciences, University of Colorado (CIRES), French Centre National de la Recherche Scientifique (YDIL-Him), DASE and DMG. The first measurements were performed in 1991 in West-Central Nepal, and in 1995 in East-Central Nepal. Sparse campaign sites in the Tibetan interior were visited between 1995 and 2007. All vectors are in the International Terrestrial Reference Frame 2000 (ITRF2000). A few GPS-derived vertical velocities are although available in Central Nepal [e.g. Larson et al., 1999; Fu and Freymueller, 2012; Ader et al., 2012]. Unfortunately, these data are too noisy to provide sufficiently robust constraints on the parameters estimated in our analysis. Therefore, they are not included in this study.

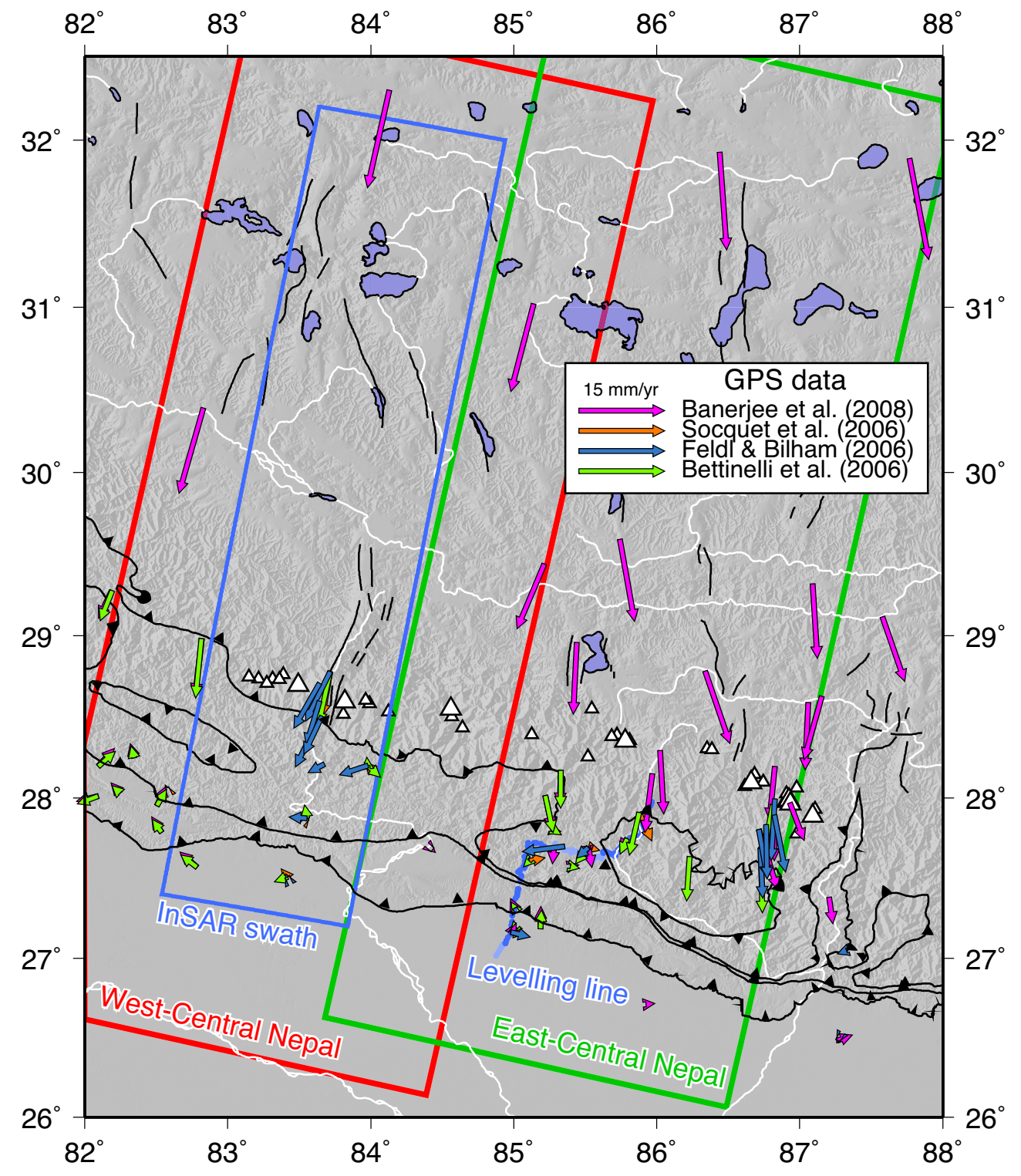

Figure S-10: GPS measurements of the horizontal component of interseismic velocity field across the Himalayan range in Central Nepal. The red and green boxes indicate the location of the two sub-regions of West-Central and East-Central Nepal, respectively. The blue box shows the location of the InSAR track analysed in this study. Leveling profile is also shown in blue. Here, the average of GPS velocity vectors located South of the MFT has been set to zero to plot the velocity field with respect to India. 


\section{Inversion procedure}

InSAR, GPS and leveling data are assumed to represent different components of the same velocity field, hereafter termed "interseismic". InSAR and leveling consist of measurements of the vertical component of the interseismic velocity field, whereas GPS constrain the two horizontal components. All GPS and leveling data points were used. However, inversion of InSAR data requires prior data decimation to decrease the number of points and ensure that the inversion is computationally efficient. This was achieved by averaging data points over regions of variable size, with the size of the region depending upon the distance from the location of the band of peak uplift in the Himalaya, following arguments developed by Grandin et al. [2009]. The size of the averaging window for InSAR data decimation increases from $5 \mathrm{~km}$ within $33 \mathrm{~km}$ of the peak uplift, to $10 \mathrm{~km}$ between $33 \mathrm{~km}$ and $100 \mathrm{~km}, 20 \mathrm{~km}$ between $100 \mathrm{~km}$ and $300 \mathrm{~km}$, and finally $40 \mathrm{~km}$ above $300 \mathrm{~km}$. This means that data points used in the inversion are more densely spaced near the region of high gradient in the velocity field, and more coarsely spaced further away where measurements are more redundant.

The forward model chosen to account for interseismic deformation is the surface displacement field produced by an infinitely-long dip-slip fault buried at depth in an elastic half-space [Okada, 1985]. The relevant parameters describing the deformation field are: fault dip, depth of the top of the dislocation, slip rate, fault location, fault strike and rake angle of slip vector. In addition, a translation of the GPS velocity vectors is required to put the different data sets in a common reference frame (for instance stable India). Similarly, we simultaneously invert for a constant offset in the InSAR and leveling data sets. For the inversions, we use the method of Tarantola and Valette [1982]. The method allows to invert for one or several parameters simultaneously, including those parameters that have a non-linear dependency upon the data vector (i.e. the geometric parameters).

The data set is split into two regions in East-Central Nepal (InSAR and GPS) and West-Central Nepal (leveling and GPS) that are examined separately (Figure S-10). Only GPS vectors within $140 \mathrm{~km}$ from the centre of the two profiles have been taken into account for the inversions. In both regions, the strike of the fault is assumed to follow the trend of the faults outcropping at the surface $\left(\mathrm{N} 110^{\circ} \mathrm{E}\right)$, which is also parallel to the trend of the microseismicity detected along the mountain range throughout Central Nepal (Figure 1). In West-Central Nepal, the fault is assumed to be purely dip-slip, which yields a convergence direction of $\mathrm{N} 10^{\circ} \mathrm{E}$, whereas in East-Central Nepal the fault is given a slight rightlateral component, yielding a convergence direction of $\mathrm{N} 05^{\circ} \mathrm{E}$. This difference accounts for the rotation of GPS vectors due to internal deformation in Tibet [e.g. Bollinger et al., 2004]. These parameters are fixed because their influence on the data is marginal (i.e. they cannot be constrained precisely from the data).

We first attempted to invert simultaneously for fault location, depth, dip, and slip rate using jointly InSAR and GPS in West-Central Nepal, and leveling and GPS in East-Central Nepal, respectively. However, inversion results are highly dependent on the relative weight of vertical versus horizontal velocity data. To tackle this difficulty, we inverted separately individual data sets, and performed a systematic parameter exploration to assess how much of each parameter can be reliably constrained by each data set. We chose to explore fault dip and fault depth, while fault latitude and slip rate were left free (Figure S-11). We found that inversion of GPS data provides a good constraint on the slip rate (18 mm/yr), a fair constraint on fault depth, but no constraint on fault dip. In contrast, the leveling data provides a poor constraint on slip rate, fault dip, and favors a fault buried at a depth greater than that required to fit the GPS $(25 \mathrm{~km}$ versus $18 \mathrm{~km})$. Similarly, InSAR data favors a somewhat deeper fault depth $(24 \mathrm{~km})$, and has small sensitivity to slip rate. However, the acceptable interval for fault dip is better constrained than for leveling or GPS, and InSAR data is best fit with a fault dipping at $6.5^{\circ}$. As expected, the fault location is highly sensitive to the location of the peak uplift in the vertical velocity field. On the other hand, the smooth horizontal velocity field does not allow to constrain precisely the location of the fault tip.

Joint vertical/horizontal inversions are expected to provide intermediate solutions in the parameter space between optimal solutions obtained from individual data sets. The difference between the solutions obtained with vertical-only or horizontal-only inversions might be partly due to inadequate assumptions in the forward model, such as an oversimplification of the fault geometry [e.g. Feldl and Bilham, 2006] or the exclusion of scenarios involving a depth-varying rigidity in the elastic half-space [Larson et al., 1999]. However, we notice that the ability of the vertical data set to constrain a model 
West-central Nepal

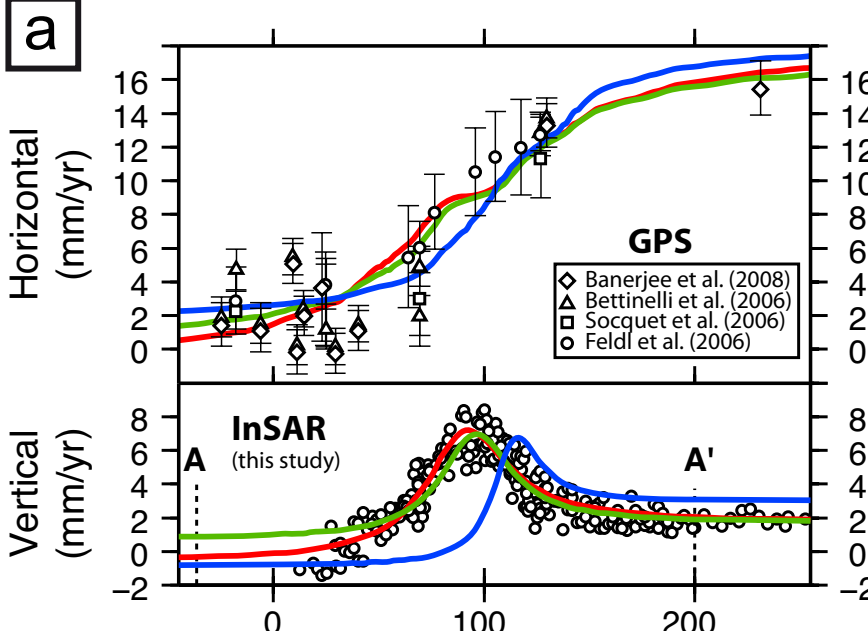

$\mathrm{N} 13^{\circ} \mathrm{E}$ projected distance from MFT $(\mathrm{km})$
East-central Nepal

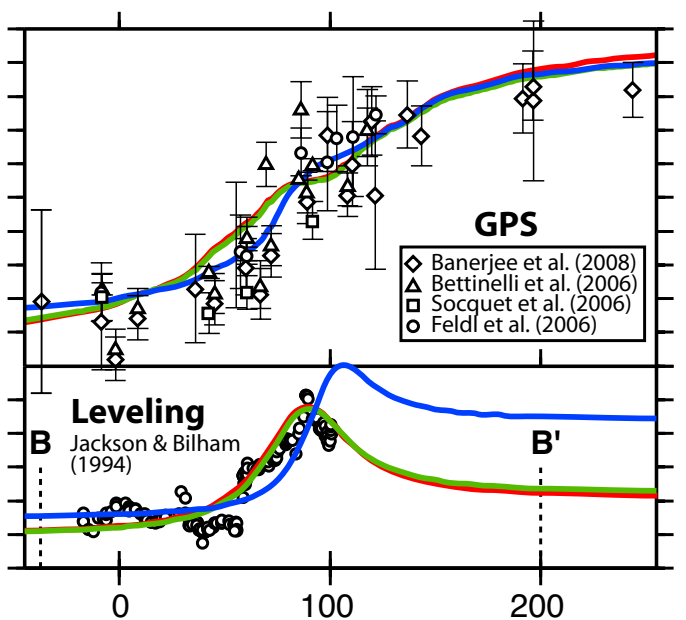

$\mathrm{N} 13^{\circ} \mathrm{E}$ projected distance from MFT $(\mathrm{km})$

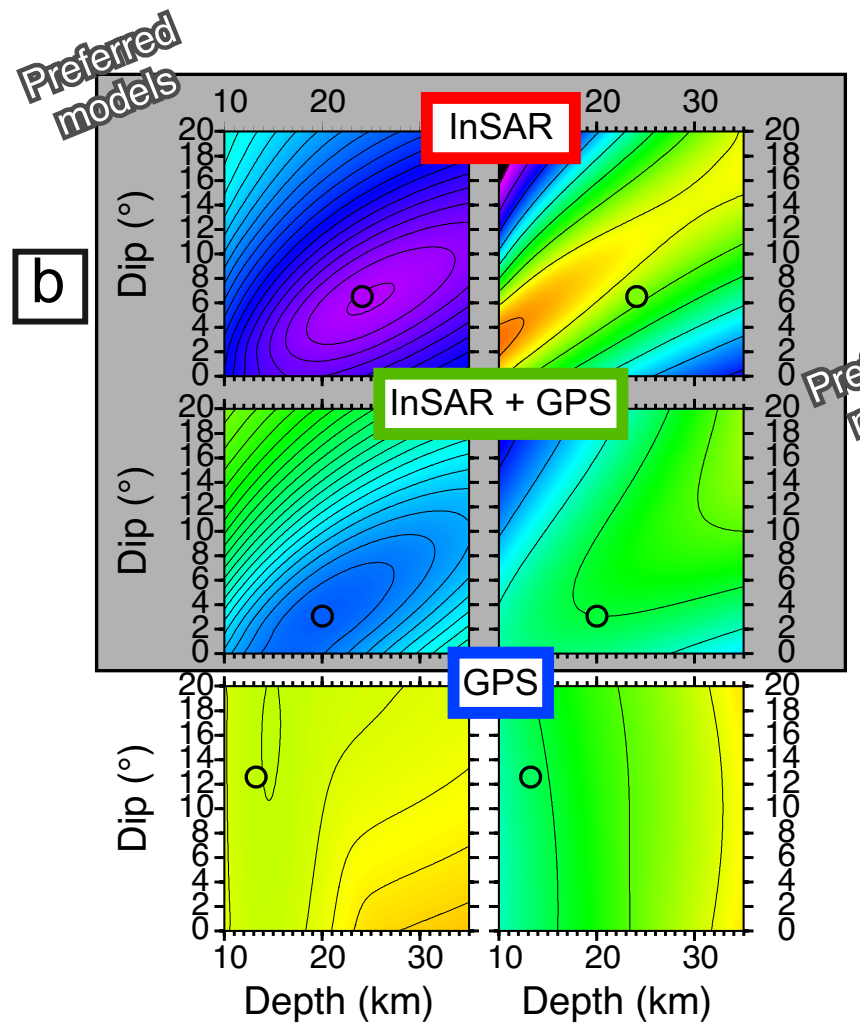

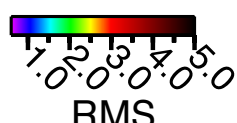

RMS

$(\mathrm{mm} / \mathrm{yr})$

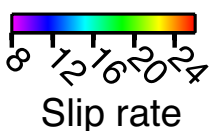

$(\mathrm{mm} / \mathrm{yr})$
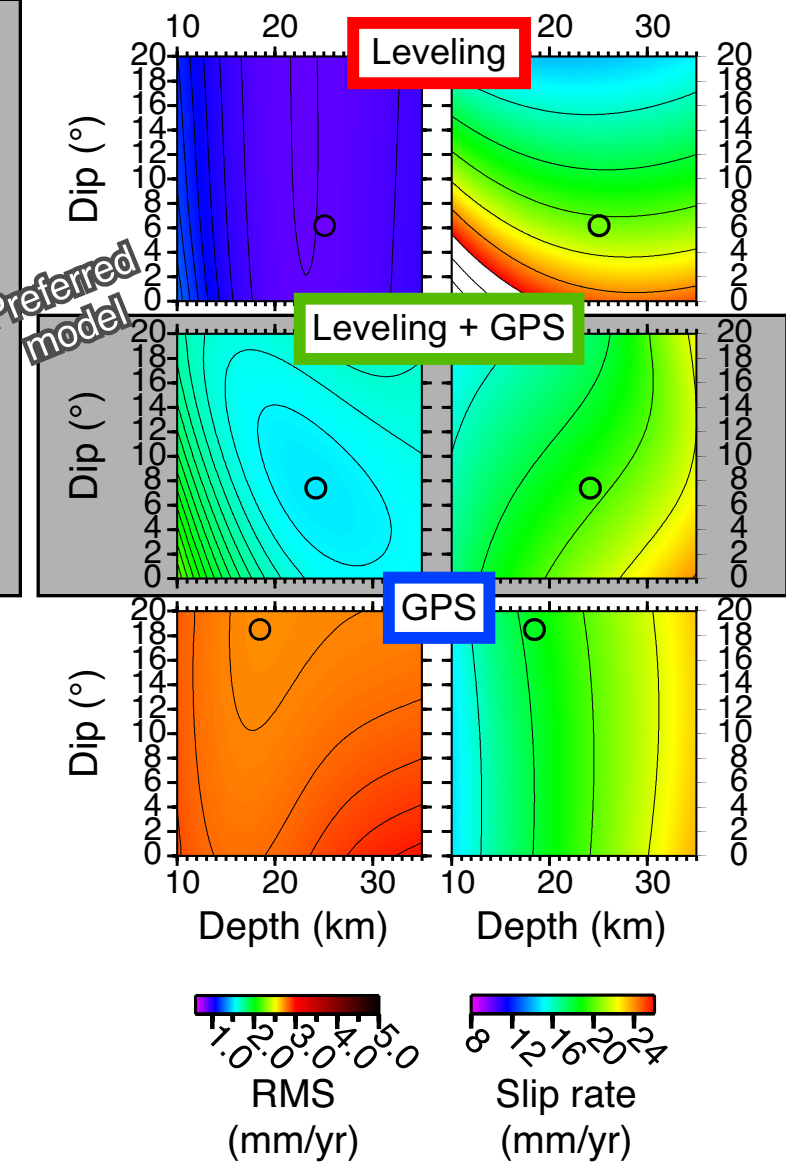

Figure S-11: (a) Horizontal (top) and vertical (bottom) components of interseismic velocity field across the Himalaya in West-Central Nepal (left) and East-Central Nepal (right). The location of profiles is indicated by the red and green boxes in Figure S-10. (b) Exploration of fault parameters using a dislocation model for the two sub-regions using different data sets as input for the inversions. For each given depth and dip of the dislocation, we invert for the optimal fault slip rate and fault location along the profile. Top panels show inversion results using vertical data only (InSAR or leveling), bottom panels show inversion results using horizontal data only (GPS), and middle panels are for joint inversion of horizontal and vertical data. In each panel, the left plot is the root-mean-square (RMS) of the residual, and the right plot is the slip rate determined for each inversion. Color dots indicate the minimum RMS location for the simultaneous inversion of the full set of parameters. Horizontal and vertical surface velocity fields predicted by each inverted fault model are shown in (a). Red: vertical only; blue: horizontal only; green: vertical and horizontal. The preferred models are highlighted by a grey box. 
that is capable of explaining the distribution of horizontal velocities is much better than the opposite (i.e. a model determined using inversion of the horizontal velocity field performs poorly in the prediction of the vertical velocity field observed otherwise). This could suggest that horizontal data has less intrinsic ability than vertical data to constrain certain model parameters. This is well captured by the calculation of the variance reduction achieved by a model determined by inversion of separate data sets (Table T-1 and Figure S-11).

In West-Central Nepal, the model obtained by inverting only the InSAR data leads to variance reduction of the GPS data by $56.5 \%$, which is near to the maximum $60.6 \%$ achieved by an inversion using GPS only. On the contrary, the "best model" determined by GPS actually increases the variance in the InSAR data by 38\%, which corresponds to a degradation of the fit to the data with respect to a null model. Similarly, in East-Central Nepal, a maximum reduction of the variance of the GPS data of $53.3 \%$ is obtained by inverting the GPS data only, which is similar to the $50.6 \%$ obtained if one inverts the leveling data only. On the contrary, the "best model" deduced from GPS only reduces the variance of the leveling by $37.4 \%$, compared to a maximum variance reduction of $62.2 \%$ achieved when inverting the leveling data only. The main reason behind this observation is the poorer constraint on the location of the tip of the fault (both its depth and its location along the profile) provided by GPS, combined with an insensitivity to fault dip. In other words, models derived from GPS predict a peak uplift that may be significantly mislocated with respect to the peak uplift measured by InSAR or leveling, thus leading to a poor fit to the vertical data (see Figure S-11a for a comparison of modeled velocity profiles for the different inversions). In addition, the uneven spatial distribution of GPS stations, as well as the significant scatter among the different data sets, make it difficult to constrain the presence of subtle changes in the North-South gradient of horizontal velocity, which are the key features that allow to constrain geometric parameters of the underlying dislocation from horizontal GPS measurements.

\section{West-central Nepal}

\begin{tabular}{|c|c|c|c|c|c|c|c|c|}
\hline & InSAR & GPS & & & & & & \\
\hline RMS data & 1.9 & 6.1 & & & & & & \\
\hline Ndata & 268 & 41 & & & & & & \\
\hline $\begin{array}{l}\text { Data used in } \\
\text { inversion }\end{array}$ & $\operatorname{Dip}\left({ }^{\circ}\right)$ & $\begin{array}{l}\text { Depth } \\
(\mathrm{km})\end{array}$ & $\begin{array}{r}\text { Slip rate } \\
(\mathrm{mm} / \mathrm{yr})\end{array}$ & $\begin{array}{c}\text { RMS InSAR } \\
(\mathrm{mm} / \mathrm{yr})\end{array}$ & $\begin{array}{l}\% \text { variance } \\
\text { reduction }\end{array}$ & $\begin{array}{l}\text { RMS GPS } \\
(\mathrm{mm} / \mathrm{yr})\end{array}$ & $\begin{array}{l}\% \text { variance } \\
\text { reduction }\end{array}$ & $\begin{array}{c}\text { RMS Total } \\
(\mathrm{mm} / \mathrm{yr})\end{array}$ \\
\hline InSAR & 6.5 & 24.1 & 20.6 & 0.7 & 60.6 & 2.7 & 56.5 & - \\
\hline InSAR+GPS & 3.0 & 20.0 & 18.0 & 0.8 & 56.4 & 2.5 & 58.5 & 1.3 \\
\hline GPS & 12.6 & 13.3 & 17.5 & 2.6 & -38.2 & 2.4 & 60.6 & - \\
\hline
\end{tabular}

\section{East-central Nepal}

\begin{tabular}{|c|c|c|c|c|c|c|c|c|}
\hline & Levelling & GPS & & & & & & \\
\hline RMS data & 2.4 & 5.9 & & & & & & \\
\hline Ndata & 170 & 56 & & & & & & \\
\hline $\begin{array}{l}\text { Data used in } \\
\text { inversion }\end{array}$ & $\operatorname{Dip}\left({ }^{\circ}\right)$ & $\begin{array}{c}\text { Depth } \\
(\mathrm{km})\end{array}$ & $\begin{array}{r}\text { Slip rate } \\
(\mathrm{mm} / \mathrm{yr})\end{array}$ & $\begin{array}{c}\text { RMS levelling } \\
(\mathrm{mm} / \mathrm{yr})\end{array}$ & $\begin{array}{l}\% \text { variance } \\
\text { reduction }\end{array}$ & $\begin{array}{c}\text { RMS GPS } \\
\text { (mm/yr) }\end{array}$ & $\begin{array}{l}\% \text { variance } \\
\text { reduction }\end{array}$ & $\begin{array}{c}\text { RMS Total } \\
(\mathrm{mm} / \mathrm{yr})\end{array}$ \\
\hline Lev & 6.2 & 25.1 & 20.5 & 0.9 & 62.2 & 2.9 & 50.6 & - \\
\hline Lev+GPS & 7.4 & 24.2 & 19.6 & 0.9 & 63.1 & 2.9 & 50.6 & 1.5 \\
\hline GPS & 18.5 & 18.5 & 18.4 & 1.5 & 37.5 & 2.7 & 53.4 & - \\
\hline
\end{tabular}

Figure T-1: Inversion results for West-Central Nepal (top) and East-Central Nepal (bottom). RMS data is the variance of the original data. Ndata: number of data points. \% variance reduction indicates the performance of each inverted model to explain the variance of the original data. The preferred models are highlighted by a grey box.

Therefore, a joint inversion of horizontal (GPS) and vertical (InSAR or leveling) velocity measurements can be significantly disturbed by inadequate GPS station distribution, or errors/biases in GPS measurements at a few individual stations. Unfortunately, these pitfalls are difficult to avoid in WestCentral Nepal, where the different GPS data sets in the area of maximum horizontal velocity gradient (approximately $70 \mathrm{~km}$ North of the MFT) show considerable scatter, with velocities spreading between $2 \mathrm{~mm} / \mathrm{yr}$ and $8 \mathrm{~mm} / \mathrm{yr}$ with respect to stable India within a distance of $10 \mathrm{~km}$ (see Figures S-10 and S11a). Therefore, in order to account for a probable underestimation of uncertainty in the GPS data, the weight of GPS data with respect to the InSAR data has to be reduced in the joint InSAR-GPS inversions. As a result, our preferred solution in West-Central Nepal lies between model parameters obtained 


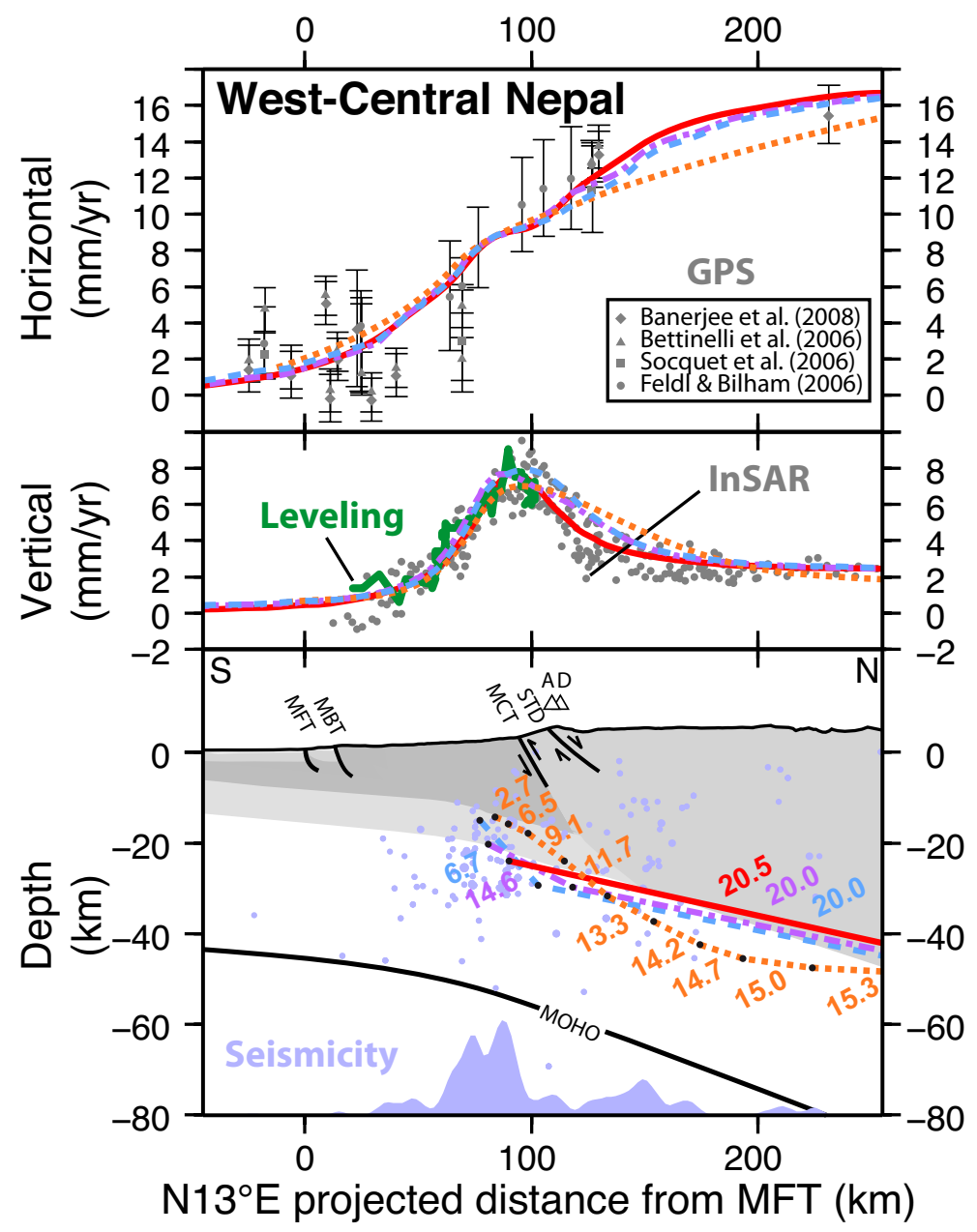

Figure S-12: Horizontal (top) and vertical (bottom) components of interseismic velocity field across the Himalaya in West-Central Nepal. Leveling data from East-Central Nepal is also shown in green for comparison. Light blue dots in the bottom panel show the 2000-2008 seismicity from the NSC catalog. Three different $2 \mathrm{D}$ dislocation models are compared, with the cross-sections showing the corresponding geometry and slip rates of sub-faults. Red: best onedislocation model determined from this study. Purple and blue: two-dislocation models with a deep shallowdipping dislocation, and a shallower, steeper dislocation with lower slip rate. Orange: model proposed by Feldl and Bilham [2006] deduced from boundaryelement modeling of GPS data. The models involving more than one dislocation are considered as representative of modeling strategies including the possibility of slip on the deeper portion of the mid-crustal ramp. The horizontal component of the predicted deformation is only marginally different among the different models, i.e. smaller than the uncertainty on the measurement. This suggests that horizontal velocity measurement are insufficient to discriminate between the different models. In contrast, the vertical velocity profiles predicted by the three models differ significantly. Models with variable dip and slip rate predict a slow decay of the uplift rate toward the North away from the peak uplift. These "longtailed" distributions are inadequate to reproduce the quasi-symmetrical uplift peak deduced from InSAR measurements.

with the joint InSAR-GPS inversion with even weighting of InSAR and GPS $\left(\mathrm{dip}=3^{\circ}\right.$; depth $=20 \mathrm{~km}$; slip rate $=18 \mathrm{~mm} / \mathrm{yr}$ ), and those obtained with the InSAR-only inversion (dip $=7^{\circ} ; \operatorname{depth}=24 \mathrm{~km}$; slip rate $=21 \mathrm{~mm} / \mathrm{yr}$ ). On the contrary, GPS data in East-Central Nepal appear to be well distributed (probably due to the more northerly location of the High range compared to West-Central Nepal) and yield a model in reasonable agreement with leveling measurements in the same area. Therefore, the result of a joint inversion of GPS and leveling is chosen as the preferred model in East-Central Nepal ( $\operatorname{dip}=7^{\circ}$; depth $=24 \mathrm{~km}$; slip rate $=20 \mathrm{~mm} / \mathrm{yr}$ ). Our preferred models are highlighted in grey in Figure S-11 and Table T-1. The corresponding fault geometries are shown in the cross-sections of Figure 2. We note that the locking depths determined from our various inversions (20-24 km) fall within the values obtained by previous studies in Central Nepal [Bettinelli et al., 2006; Socquet et al., 2006; Feldl and Bilham, 2006; Banerjee et al., 2008].

We have also tested alternative models involving more than one dislocation, which could account for a more complex fault geometry, and include possible interseismic slip on the deep part of the mid-crustal ramp. However, the parameter space for such models cannot be explored exhaustively. In Figure S-12, we present three models representative of two alternative modeling strategies, using the data set of West-Central Nepal (InSAR and GPS) to compare predicted and observed velocity profiles. In the first model (in purple in Figure S-12), two dislocations are included: a deep $6^{\circ}$-dipping dislocation of semi-infinite width with a prescribed slip rate of $20 \mathrm{~mm} / \mathrm{yr}$ connected at $30 \mathrm{~km}$ depth with a shallower, steeper dislocation reaching $20 \mathrm{~km}$ depth. The dip of the shallow dislocation $\left(15^{\circ}\right)$ is fixed such that the updip projection of the dislocation at the surface roughly corresponds to the MFT. We invert for the slip rate on the shallow dislocation and for the latitudinal location of the pair of dislocations. The best model yields a null slip on the shallower dislocation and a tip for the steeper dislocation located beneath the uplift peak. This means that a single dislocation provides the best fit for this inversion (albeit yielding a poor fit to the data compared to the optimal shallower dislocation model described above and in the main text). However, a strong trade-off is found between the two inverted parameters: the lower the latitude, the lower the inverted slip rate on the mid-crustal dislocation. This shows that the slip rate must be low South of the peak uplift measured by InSAR. To overcome this difficulty, 
we arbitrarily fixed the latitude of the dislocation pair so that the upper dislocation is located roughly beneath the peak uplift, which yields an inverted slip rate on the shallow dislocation of $14.6 \mathrm{~mm} / \mathrm{yr}$. Such a model could be compatible with partial locking on the deeper part of the mid-crustal ramp. The same behaviour is observed if the dip of the shallowest dislocation is set to $30^{\circ}$ between $30 \mathrm{~km}$ and $15 \mathrm{~km}$ depth, thus simulating the presence of the mid-crustal ramp. For this second model, we also find a reduced slip rate of $6.7 \mathrm{~mm} / \mathrm{yr}$ on the mid-crustal ramp (in blue in Figure $\mathrm{S}-12$ ). The same results are obtained when trying to determine the optimal depth and latitudinal location of a fault including one kink (from $6^{\circ}$ to $30^{\circ}$ dip), divided into several segments to allow for a tapered slip profile on the fault. The best fit to the data is obtained when the deep, shallow-dipping part of the dislocation coincides with our single dislocation model that provides the best fit (Figure 2), and when the shallower, steeply-dipping segments have a null slip.

In a third model (in orange in Figure S-12), Feldl and Bilham [2006] proposed a more complex modeling of the creeping section of MHT. In this model, tapering of the interseismic slip rate towards the surface was determined by boundary-element modeling of horizontal GPS data given a prescribed sigmoidal geometry of the fault at depth. The deepest flat-lying elements slip at a rate $>15 \mathrm{~mm} / \mathrm{yr}$ (up to $25 \mathrm{~mm} / \mathrm{yr}$ beyond $500 \mathrm{~km}$ from the tip of the creeping fault).

All the models discussed here predict similar horizontal velocity profiles, in agreement with observations (Figure S-12, top). This again suggests that knowledge of the horizontal component of the interseismic velocity field is insufficient to precisely constrain the geometry of the underlying fault system. However, the models involving several dislocations always seem to produce a broad peak of uplift, thus failing to reproduce the rapid decay of the vertical uplift velocity toward the North (Figure S-12, middle). In contrast, a single-dislocation model succeeds in fitting the nearly symmetrical shape of the uplift peak, which supports the existence of a sharp transition between a deep creeping section and a shallower locked section of the fault. Because the leveling profile is limited to the Nepal territory, this ambiguity among different models could not be resolved in previous studies [e.g. Jackson and Bilham, 1994]. Therefore, the single dislocation model is our preferred one. 


\section{Seismic catalogue}

The National Seismological Centre (NSC) from the Nepalese Department of Mines and Geology monitors the seismicity using a network of 21 short-period stations deployed within the frame of a long lasting collaboration with CEA/DASE (France). The seismic events are located using a 3 layers 1D-velocity model, characterizing the velocities for depths of $0-23 \mathrm{~km}, 23-55 \mathrm{~km}$ and more than $55 \mathrm{~km}$ with $P$-wave velocities respectively of $5.6,6.1$ and $8.1 \mathrm{~km} / \mathrm{s}[$ Pandey, 1985]. The seismic events located within the network, which is the case for the mid-crustal events reported here on the cross sections through the High Himalayan range, are located within $1 \sigma$ confidence ellipses typically smaller than 10-15 km, with less than $10 \mathrm{~km}$ uncertainty on their depths [e.g. Pandey et al., 1995]. Note that the mid-crustal cluster is more diffuse in West Central Nepal than in East Central Nepal (Figure 2), which is most probably related to the lower station density and azimuth coverage. A temporary experiment with 3 additional seismic stations deployed from July to December 1995 around the mid-crustal cluster North of Kathmandu suggested that the hypocentral depths determined on routine basis may be overestimated in this region by $5 \mathrm{~km}$ [Pandey et al., 1999]. Although similar biases could also affect the hypocentral depths in West-Central Nepal, this result has not been taken into account to correct any depths in Figure 2.

\section{River denudation profiles}

Lavé and Avouac [2001] have determined riverbed erosion profiles along major rivers of Central Nepal crossing the active tectonic structures of the Himalayan orogen. In lowland Nepal, incision through the rising anticline associated with the MFT gives rise to a series of nested strath terraces that were used to determine the uplift rate. At higher elevation, modern channel topographic slope and width were used to infer denudation rates via an empiric relationship involving river discharge and watershed surface area. The resulting profiles show a bimodal distribution of erosion in Central Nepal. A first sharp peak (maximum $\sim 10 \mathrm{~mm} / \mathrm{yr}$ ) is associated with the frontal outbreak of MHT near the MFT. A second broader peak (maximum $\sim 7 \mathrm{~mm} / \mathrm{yr}$ ) located $\sim 100 \mathrm{~km}$ inland in the High Himalaya is loosely colocated with the surface trace of the MCT. Two rivers profiles are of particular interest for our study. (1) The Kali Gandaki river drains the Thakkhola graben, and follows our InSAR profile in West-Central Nepal. (2) The upper part of the leveling profile in East-Central Nepal corresponds to the trace of the Sun Kosi km North of the MFT, respectively. In Figure 2, we have represented the average erosion profile deduced from stacking the 6 profiles, and we have set the location of the peak in the High Himalaya to fit the location of the peak deduced from the two rivers in their respective sub-region. In Figure 3, we have represented the expected erosion profile for three models of mountain growth (black curves). The profile in Figure 3A is from Cattin and Avouac [2000], who predict that a prominent uplift peak should be located where the MFT intersects the surface (first peak), while another broader uplift peak in the High Himalaya occurs above the mid-crustal ramp within the MHT (second peak). In Figure 3B, we have assumed that half of the convergence is accommodated by thrusting along the MFT (first peak), while the remaining convergence is accommodated by out-of-sequence thrusting near the surface trace of the MCT (second peak). In Figure 3C, the uplift peak above the ramp predicted by the steady-state model of Cattin and Avouac [2000] has been shifted to the North above an abandoned ramp, in order to simulate the impact of a recent southward migration of the mid-crustal ramp whose effect on the long-term uplift profile would not yet be expressed in riverbed morphology. 


\section{References}

Ader, T., J.-P. Avouac, J. Liu-Zheng, H. Lyon-Caen, L. Bollinger, J. Galetzka, J. Genrich, M. Thomas, K. Chanard, S. N. Sapkota, S. Rajaure, P. Shrestha, L. Ding, and M. Flouzat (2012), Convergence rate across the Nepal Himalaya and interseismic coupling on the Main Himalayan Thrust: Implications for seismic hazard, J. Geophys. Res., 117, B04,403, doi:10.1029/2011JB009071.

Banerjee, P., R. Bürgmann, B. Nagarajan, and E. Apel (2008), Intraplate deformation of the Indian subcontinent, Geophys. Res. Lett., 35, L18301, doi:10.1029/2008GL035468.

Bettinelli, P., J.-P. Avouac, M. Flouzat, F. Jouanne, L. Bollinger, P. Willis, and G. J. Chitrakar (2006), Plate motion of India and interseismic strain in the Nepal Himalaya from GPS and DORIS measurements, Journal of Geodesy, 80, 567-589, doi:10.1007/s00190-006-0030-3.

Bollinger, L., J. P. Avouac, R. Cattin, and M. R. Pandey (2004), Stress buildup in the Himalaya, J. Geophys. Res., 109 (B18), B11405, doi:10.1029/2003JB002911.

Cattin, R., and J. P. Avouac (2000), Modeling mountain building and the seismic cycle in the Himalaya of Nepal, $J$. Geophys. Res., 105, 13,389-13,408, doi:10.1029/2000JB900032.

Davidson, G. W., and R. Bamler (1999), Multiresolution phase unwrapping for SAR interferometry, IEEE Transactions on Geoscience and Remote Sensing, 37, 163-174, doi:10.1109/36.739150.

Doin, M.-P., S. Guillaso, R. Jolivet, C. Lasserre, F. Lodge, G. Ducret, and R. Grandin (2011), Presentation of the small baseline NSBAS processing chain on a case example: the Etna deformation monitoring from 2003 to 2010 using Envisat data, in Proceedings of the European Space Agency (ESA) "Fringe" Symposium, Frascati, Italy.

Ducret, G., M. P. Doin, R. Grandin, C. Lasserre, and S. Guillaso (2011), DEM corrections before unwrapping in a small baseline strategy for insar time series analysis, in Proceedings of the IEEE International Geoscience and Remote Sensing Symposium, Vancouver, Canada.

Farr, T. G., P. A. Rosen, E. Caro, R. Crippen, R. Duren, S. Hensley, M. Kobrick, M. Paller, E. Rodriguez, L. Roth, D. Seal, S. Shaffer, J. Shimada, J. Umland, M. Werner, M. Oskin, D. Burbank, and D. Alsdorf (2007), The Shuttle Radar Topography Mission, Reviews of Geophysics, 45, RG2004, doi:10.1029/2005RG000183.

Feldl, N., and R. Bilham (2006), Great Himalayan earthquakes and the Tibetan plateau, Nature, 444, 165-170, doi: 10.1038/nature05199.

Fu, Y., and J. T. Freymueller (2012), Seasonal and long-term vertical deformation in the Nepal Himalaya constrained by GPS and GRACE measurements, J. Geophys. Res., 117, B03407, doi:10.1029/2011JB008925.

Gatelli, F., A. M. Guarnieri, F. Parizzi, P. Pasquali, C. Prati, and F. Rocca (1994), Wavenumber shift in SAR interferometry, IEEE Transactions on Geoscience and Remote Sensing, 32, 855-865, doi:10.1109/36.298013.

Grandin, R., A. Socquet, R. Binet, Y. Klinger, E. Jacques, J. B. de Chabalier, G. C. P. King, C. Lasserre, S. Tait, P. Tapponnier, D. A., and P. P. (2009), September 2005 Manda Hararo-Dabbahu rifting event, Afar (Ethiopia): Constraints provided by geodetic data, J. Geophys. Res., 114(B08404), doi:10.1029/2008JB005843.

Jackson, M., and R. Bilham (1994), Constraints on Himalayan deformation inferred from vertical velocity fields in Nepal and Tibet, J. Geophys. Res., 99, 13,897, doi:10.1029/94JB00714.

Jolivet, R., R. Grandin, C. Lasserre, M.-P. Doin, and G. Peltzer (2011), Systematic InSAR tropospheric phase delay corrections from global meteorological reanalysis data, Geophys. Res. Lett., 38, L17311, doi:10.1029/2011GL048757.

Larson, K. M., R. Bürgmann, R. Bilham, and J. T. Freymueller (1999), Kinematics of the India-Eurasia collision zone from GPS measurements, J. Geophys. Res., 104, 1077-1094, doi:10.1029/1998JB900043.

Lavé, J., and J. P. Avouac (2001), Fluvial incision and tectonic uplift across the Himalayas of central Nepal, J. Geophys. Res., 106, 26,561-26,592, doi:10.1029/2001JB000359.

Okada, Y. (1985), Surface deformation due to shear and tensile faults in a half space, Bull. Seismol. Soc. Am., 75(4), 1135-1154.

Pandey, M., R. P. Tandukar, J.-P. Avouac, J. Vergne, and T. Heritier (1999), Seismotectonics of the Nepal Himalaya from a local seismic network, Journal of Asian Earth Sciences, 17, 703-712, doi:10.1016/S1367-9120(99)00034-6.

Pandey, M. R. (1985), Seismic model of central and eastern lesser Himalaya of Nepal, Journal of Nepal Geological Society, $3,1-11$.

Pandey, M. R., R. P. Tandukar, J. P. Avouac, J. Lave, and J. P. Massot (1995), Interseismic strain accumulation on the Himalayan Crustal Ramp (Nepal), Geophys. Res. Lett., 22, 751-754, doi:10.1029/94GL02971.

Pinel-Puysségur, B., R. Michel, and J.-P. Avouac (2011), Multi-link SAR interferograms: enhancement of a wrapped interferometric database, in Proceedings of the IEEE International Geoscience and Remote Sensing Symposium, Vancouver, Canada.

Rosen, P. A., S. Henley, G. Peltzer, and M. Simons (2004), Updated Repeat Orbit Interferometry Package Released, Eos Trans. AGU, 85(5), 47-47, doi:10.1029/2004EO050004.

Socquet, A., C. Vigny, N. Chamot-Rooke, W. Simons, C. Rangin, and B. Ambrosius (2006), India and Sunda plates motion and deformation along their boundary in Myanmar determined by GPS, J. Geophys. Res., 111(B10), B05406, doi:10.1029/2005JB003877.

Tarantola, A., and B. Valette (1982), Generalized Nonlinear Inverse Problems Solved Using the Least Squares Criterion, Rev. Geophys., 20, 219-232.

Zandbergen, R., M. Otten, P. L. Righetti, D. Kuijper, and J. M. Dow (2003), Routine operational and high-precision orbit determination of envisat, Advances in Space Research, 31, 1953-1958, doi:10.1016/S0273-1177(03)00154-6. 